\title{
One Episode of Self-Resolving Plasmodium yoelii Infection Transiently Exacerbates Chronic Mycobacterium tuberculosis Infection
}

\author{
Jannike Blank ${ }^{1}$, Lars Eggers ${ }^{1}$, Jochen Behrends ${ }^{2}$, Thomas Jacobs ${ }^{3}$ and \\ Bianca E. Schneider ${ }^{1 *}$ \\ ${ }^{1}$ Division of Coinfection, Priority Research Area Infections, Research Center Borstel, Borstel, Germany, ${ }^{2}$ Fluorescence \\ Cytometry Core Facility, Research Center Borstel, Borstel, Germany, ${ }^{3}$ Department of Immunology, Bernhard Nocht Institute \\ for Tropical Medicine, Hamburg, Germany
}

\section{OPEN ACCESS}

Edited by:

Johnan A. R. Kaleeba

Uniformed Services University of the

Health Sciences, USA

Reviewed by:

Martin James Holland, London School of Hygiene and Tropical Medicine, UK

Paras Jain,

Albert Einstein College of Medicine,

USA

*Correspondence: Bianca E. Schneider bschneider@fz-borstel.de

Specialty section: This article was submitted to

Infectious Diseases,

a section of the journal

Frontiers in Microbiology

Received: 30 November 2015 Accepted: 27 January 2016

Published: 15 February 2016

Citation:

Blank J, Eggers L, Behrends J, Jacobs $T$ and Schneider BE (2016)

One Episode of Self-Resolving Plasmodium yoelii Infection Transiently Exacerbates Chronic Mycobacterium tuberculosis Infection.

Front. Microbiol. 7:152. doi: 10.3389/fmicb.2016.00152
Malaria and tuberculosis (Tb) are two of the main causes of death from infectious diseases globally. The pathogenic agents, Plasmodium parasites and Mycobacterium tuberculosis, are co-endemic in many regions in the world, however, compared to other co-infections like HIV/Tb or helminth/Tb, malaria/Tb has been given less attention both in clinical and immunological studies. Due to the lack of sufficient human data, the impact of malaria on Tb and vice versa is difficult to estimate but co-infections are likely to occur very frequently. Due to its immunomodulatory properties malaria might be an underestimated risk factor for latent or active Tb patients particularly in highendemic malaria settings were people experience reinfections very frequently. In the present study, we used the non-lethal strain of Plasmodium yoelii to investigate, how one episode of self-resolving malaria impact on a chronic $M$. tuberculosis infection. $P$. yoelii co-infection resulted in exacerbation of $\mathrm{Tb}$ disease as demonstrated by increased pathology and cellular infiltration of the lungs which coincided with elevated levels of pro- and anti-inflammatory mediators. T cell responses were not impaired in co-infected mice but enhanced and likely contributed to increased cytokine production. We found a slight but statistically significant increase in $M$. tuberculosis burden in co-infected animals and increased lung CFU was positively correlated with elevated levels of TNF $\alpha$ but not IL-10. Infection with $P$. yoelii induced the recruitment of a $\mathrm{CD} 11 \mathrm{C}^{+}$population into lungs and spleens of $M$. tuberculosis infected mice. $\mathrm{CD}_{11 \mathrm{C}^{+}}$cells isolated from $P$. yoelii infected spleens promoted survival and growth of $M$. tuberculosis in vitro. 170 days after $P$. yoelii infection changes in immunopathology and cellular immune responses were no longer apparent while $M$. tuberculosis numbers were still slightly higher in lungs, but not in spleens of co-infected mice. In conclusion, one episode of $P$. yoelii co-infection transiently exacerbated disease severity but had no long-term consequences on disease progression and survival of $M$. tuberculosis infected mice.

Keywords: Mycobacterium tuberculosis, Plasmodium yoelii, malaria, tuberculosis, co-infection, mouse model 


\section{INTRODUCTION}

Tuberculosis $(\mathrm{Tb})$ and malaria are the most prevalent bacterial and parasitic infections in humans, respectively, and continue to be major causes of morbidity and mortality in impoverished regions in the tropics. The causative agent of Tb, Mycobacterium tuberculosis is carried by an estimated 2-3 billion people globally, but in most cases it lies dormant and the immune system is able to prevent it from spreading in the body (WHO, 2015). A relatively small proportion (5-15\%) of M. tuberculosis-infected people will develop active disease during their lifetime. However, the immune system fails to achieve sterile eradication of the tubercle bacillus. The enormous reservoir of latent $\mathrm{Tb}$ patients constantly leads to new active $\mathrm{Tb}$ cases and transmission of the disease, thus perpetuating the epidemic. The reasons why some people develop active $\mathrm{Tb}$, while others contain the infection remain enigmatic. Reactivation can occur after years or decades of clinical latency, and the risk of reactivation increases with conditions that modulate the immune status of the host such as disease (most prominent HIV/AIDS), drug treatment, age, or malnutrition (O'Garra et al., 2013).

Malaria is highly prevalent in populations where M. tuberculosis is endemic. 3.3 billion people are at risk of being infected with the causative agent, protozoan parasites of the genus Plasmodium. In 2013, approximately 200 million cases of malaria led to 600,000 deaths, predominately in young children under the age of 5 and pregnant women in sub-Saharan Africa (Murray et al., 2012). In malaria-endemic areas, immunity slowly develops over time, which does not prevent reinfection but limits parasite density and symptoms. Consequently, the majority of Plasmodium infections in adults are mild or asymptomatic (Bousema et al., 2014). However, the public health impact of malaria goes beyond the direct burden of the disease. Both symptomatic and asymptomatic malarial infections can cause immune modulation, which has long been discussed to account for constant malaria reinfections, reduced vaccine efficacy as well as for an increased susceptibility to secondary infections (including bacteria such as Salmonella or viruses such as Herpes virus and Epstein-Barr virus; Greenwood et al., 1972; Bomford and Wedderburn, 1973; Warren and Weidanz, 1976; Williamson and Greenwood, 1978; Correa et al., 1980; Brasseur et al., 1983; Whittle et al., 1984; Cook, 1985; Mabey et al., 1987; Hviid et al., 1991; Cunnington and Riley, 2010; Walther et al., 2012). Epidemiological studies showed that death rates in adults and children declined considerably when the incidence of malaria was reduced, while the entire reduction in death rates could not be directly attributed to malaria (Enwere et al., 1999; Kleinschmidt et al., 2009; Cunnington and Riley, 2010). This was already noted back in the 19th century, where post-mortem examinations revealed that deaths secondary to malaria were at least as great as mortality directly attributed to malaria infection and correlated with co-endemic infectious diseases such as $\mathrm{Tb}$, pneumonia and diarrhea (Shanks et al., 2008). In line with this is a more recent clinical study in Guinea-Bissau, which reported improved clinical outcome and reduced mortality among severely ill $\mathrm{Tb}$ patients after malaria prevention had been carried out (Colombatti et al., 2011).
Most of the experimental studies on co-infection between mycobacteria and Plasmodium focus on the unspecific protective effects of mycobacterial infections against malaria (Clark et al., 1976; Murphy, 1981; Matsumoto et al., 2000; Page et al., 2005; Mueller et al., 2012). The majority of such studies addressed the question as to whether the widely used $\mathrm{Tb}$ vaccine strain M. bovis Bacille Calmette Guerin (BCG) confers non-specific protection against subsequent Plasmodium infection (Clark et al., 1976; Smrkovski and Strickland, 1978; Matsumoto et al., 2000; Leisewitz et al., 2008; Parra et al., 2013) since BCG has been associated with reduced child mortality from causes other than Tb (Roth et al., 2005, 2006a,b; Shann 2010, 2011). In contrast, only two experimental studies including our own investigated the outcome of virulent $M$. tuberculosis infection in the context of malaria co-infection in the mouse model and indeed found the control of $M$. tuberculosis to be impaired in the presence of different rodent malaria parasites (Scott et al., 2004; Mueller et al., 2012). In our previous study, we reported that co-infection with $P$. berghei NK65, a lethal strain causing malaria-associated acute respiratory distress syndrome in C57BL/6 mice (Van den Steen et al., 2010), was associated with enhanced inflammatory immune responses and tissue pathology, hypercytokinemia and altered T-cell responses which resulted in impaired control of chronic M. tuberculosis infection (Mueller et al., 2012). Similarly, co-infection with the non-lethal strain of $P$. yoelii interfered with the containment of $M$. tuberculosis although to a lesser extent (Scott et al., 2004). The immunological mechanisms have not been studied in detail.

\section{MATERIALS AND METHODS}

\section{Ethics Statement}

Animal experiments were approved by the Ethics Committee for Animal Experiments of the Ministry for Agriculture, Environment, and Rural Areas of the State of Schleswig-Holstein (Kommission für Tierversuche/Ethik-Kommission des Landes Schleswig-Holstein) under the license 33-3/10 ("Die Auswirkung von Tuberkulose auf die Pathogenese und Immunantwort bei Malaria im Rahmen einer Koinfektion in der Maus"/ "The impact of tuberculosis on pathogenesis and immune responses to malaria in an experimental co-infection mouse model").

\section{Mice, Bacterial Infection, and Colony Forming Units}

For all in vivo experiments female C57BL/6 mice aged between 6 and 8 weeks were used, which were obtained from Charles River Laboratories. Mice were maintained under specific barrier conditions in BSL 3 facilities. For all in vitro experiments female and male C57BL/6 wild-type and female transgenic OT2 mice aged between 8 and 20 weeks were used, bred in the animal facility of the Research Center Borstel.

Mycobacterium tuberculosis $\mathrm{H} 37 \mathrm{Rv}$ was grown in Middlebrook 7H9 broth (BD Biosciences) supplemented with $10 \%$ v/v OADC (Oleic acid, Albumin, Dextrose, Catalase) enrichment medium (BD Biosciences). Bacterial cultures were harvested, resuspended in $\mathrm{PBS} / 10 \%$ glycerol, and aliquots were 
frozen at $-80^{\circ} \mathrm{C}$ until later use. Viable cell counts in thawed aliquots were determined by plating serial dilutions onto Middlebrook $7 \mathrm{H} 11$ agar plates supplemented with $10 \% \mathrm{v} / \mathrm{v}$ heat-inactivated bovine serum, $0.1 \% \mathrm{w} / \mathrm{v}$ asparagine and $0.5 \%$ v/v glycerol followed by incubation at $37^{\circ} \mathrm{C}$.

For infection of experimental animals, M. tuberculosis stocks were diluted in sterile distilled water at a concentration providing an uptake of 200 viable bacilli per lung. Infection was performed via the respiratory route by using an aerosol chamber (Glas-Col, Terre-Haute, IN, USA). Animals were exposed for $40 \mathrm{~min}$ to an aerosol generated by nebulizing the prepared $M$. tuberculosis suspension. The inoculum size was quantified $24 \mathrm{~h}$ after infection by determining bacterial loads in the lungs of infected mice. Bacterial loads in lung, liver, and spleen were evaluated at different time points after aerosol infection by mechanical disruption of the organs in $0.05 \% \mathrm{v} / \mathrm{v}$ Tween 20 in PBS containing a proteinase inhibitor cocktail (Roche) prepared according to the manufacturer's instructions. Tenfold serial dilutions of organ homogenates in sterile water $/ 1 \% \mathrm{v} / \mathrm{v}$ Tween $80 / 1 \%$ w/v albumin were plated onto Middlebrook 7H11 agar plates and incubated at $37^{\circ} \mathrm{C}$. Colonies were enumerated after 3-4 weeks.

\section{Parasitic Infection}

Plasmodium yoelii 17NL (non-lethal) was maintained by regular passage in NMRI mice. For cryopreservation, blood was collected from highly parasitemic mice, and aliquots were stored in liquid nitrogen in a solution of $0.9 \% \mathrm{NaCl}, 4.6 \%$ sorbitol, and $35 \%$ glycerol. Experimental naïve mice or animals pre-infected for 30 days with $M$. tuberculosis were infected intraperitoneally (i.p.) with $1 \times 10^{5}$ P. yoelii-infected RBCs obtained from a homologous donor, which had been infected from frozen stock. Parasitemia was determined on Giemsa-stained blood smears from tail blood every 2 to 3 days. Moreover, mice were checked for P. yoeliiinduced anemia based on the hemoglobin concentration in the blood. For this, tail vein blood was collected and diluted in Drabkin's Solution supplemented with Brij L23 Solution (Sigma-Aldrich). Optical density of hemoglobin was measured at $540 \mathrm{~nm}$.

\section{Cell Isolation and Purification from Lungs and Spleens}

Mice were sacrificed 51 or 200 days p.i. with M. tuberculosis and perfused intracardially with $20 \mathrm{ml}$ PBS to remove circulating leukocytes from the tissue. Lungs were digested in $100 \mu \mathrm{g} / \mathrm{ml}$ DNase I (Roche) and $50 \mu \mathrm{g} / \mathrm{ml}$ Liberase TL (Roche) in RPMI for $90 \mathrm{~min}$ and passed through a $100 \mu \mathrm{m}$ pore size cell strainer to obtain a single cell suspension. Spleens were passed through a $100 \mu \mathrm{m}$ pore size cell strainer. Remaining erythrocytes in lung and spleen cell suspensions were lysed $\left(155 \mathrm{mM} \mathrm{NH}_{4} \mathrm{Cl}, 10 \mathrm{mM}\right.$ $\mathrm{KHCO}_{3}, 0.1 \mathrm{mM}$ EDTA in $\mathrm{H}_{2} \mathrm{O}$ ) and cells were resuspended in RPMI 1640 supplemented with $2 \mathrm{mM}$ L-glutamine, 1\% v/v Hepes, $50 \mu \mathrm{M} \beta$-mercaptoethanol and $10 \% \mathrm{v} / \mathrm{v}$ heat-inactivated fetal calf serum (complete RPMI 1640 medium). Cell numbers were determined with the Vi-CELL Cell Viability Analyzer (Beckman Coulter).

\section{Flow Cytometry}

For flow cytometric analysis of surface markers and intracellular cytokines, single cell suspensions of lungs, spleens, or cell cultures were stained with optimal concentrations of the following specific antibodies: CD45-V450, CD4-V500, CD8V450, and CD62L-APC from BD Biosciences, CD3-PerCP-Cy5.5, CD4-BV510, CD4-PE-Cy7, CD8a-FITC, CD44-FITC, CD19PE, CD80-AF488, CD86-APC, Ly6G-APC-Cy7, CD11c-PE-Cy7, NK1.1-PE-Cy7, TNF $\alpha$-Pacific Blue, IFN $\gamma$-PerCP-Cy5.5, IL-17APerCP-Cy5.5, IL-2-PE-Cy7, and IL-10-PE from BioLegend and CD90.2-eFluor780 from eBioscience. Data were acquired on a FacsCantoII ${ }^{\circledR}$ flow cytometer (BD Biosciences) equipped with a 405, 488, and $633 \mathrm{~nm}$ laser and analyzed with the FCS Express software (DeNovo ${ }^{\text {TM }}$ Software).

\section{Intracellular Cytokine Staining}

Single cell suspensions of lungs or spleens $\left(1 \times 10^{6}\right)$ were stimulated $4.5 \mathrm{~h}$ with $\alpha \mathrm{CD} 3 \mathrm{e} / \alpha \mathrm{CD} 28$ (BioLegend; $5 \mu \mathrm{g} / \mathrm{ml}$, respectively) in the presence of GolgiPlug ${ }^{\mathrm{TM}}$ (BD Biosciences, contains Brefeldin A). Non-specific antibody binding was blocked by incubation with a cocktail containing anti-Fc $\gamma$ RIII/II $\mathrm{mAb}$ (BioLegend), mouse, hamster and rat serum. Subsequently, cells were stained with directly labeled anti-CD90.2, anti-CD44, anti-CD4, and anti-CD8a antibodies for $20 \mathrm{~min}$ at $4^{\circ} \mathrm{C}$. After washing, cells were fixed and permeabilized over night with Cytofix/Cytoperm ${ }^{\mathrm{TM}}$ (BD Biosciences). Cells were washed with Perm/Wash buffer ${ }^{\mathrm{TM}}$ (BD Biosciences) and stained with directly labeled anti-IFN $\gamma$, anti-IL-10, anti-IL-17A, anti-IL-2, and anti$\mathrm{TNF} \alpha$ antibodies for $45 \mathrm{~min}$ at $4^{\circ} \mathrm{C}$.

\section{Histology}

Superior lobes of lungs from infected mice were fixed with $4 \% \mathrm{w} / \mathrm{v}$ PFA for $24 \mathrm{~h}$ and embedded in paraffin. Sections $(4 \mu \mathrm{m})$ were rehydrated by running through xylenes, alcohols of decreasing concentrations and finally water. Sections were stained with hematoxylin and eosin (Merck) and/or carbol fuchsin (Merck) followed by decolorization with acid-alcohol to visualize mycobacteria in the lungs and analyzed with a BX41 light microscope and cell^ $\mathrm{B}$ software. Histological sections of infected lungs were scored in a blinded manner. Affected lung area was quantified in relation to whole lung area using cell^ $\mathrm{B}$ area measurement.

\section{RNA Isolation, cDNA-Synthesis, and Quantitative Real-Time PCR}

Total RNA from lung tissue was extracted using TRIzol ${ }^{\circledR}$ reagent (Invitrogen) and the Direct-zol ${ }^{\mathrm{TM}}$ RNA MiniPrep Kit (Zymo Research) as recommended by the manufacturer. For quantitative real-time PCR, 400 ng of total RNA were reverse transcribed using Maxima First Strand cDNA Synthesis Kit for RT-qPCR (Life Technologies) according to the manufacturer's instruction at $25^{\circ} \mathrm{C}$ for $10 \mathrm{~min}, 55^{\circ} \mathrm{C}$ for $30 \mathrm{~min}, 85^{\circ} \mathrm{C}$ for $3 \mathrm{~min}$. Real-time quantitative PCR reactions were performed using LightCycler ${ }^{\circledR}$ 480 SYBR Green I Master (Roche). PCR amplifications were performed in duplicates in a total volume of $10 \mu \mathrm{l}$, containing $1 \mu \mathrm{l}$ cDNA sample, $0.2 \mu \mathrm{l}$ of primer pairs $(10 \mu \mathrm{M}), 5 \mu \mathrm{l}$ 
SYBR green mix, and $3.8 \mu \mathrm{l}$ RNase/DNase-free water. Data analysis was performed using the LightCycler ${ }^{\circledR} 480$ instrument. The PCR cycling conditions used were as follows: (I) Preincubation/denaturation: $95^{\circ} \mathrm{C}$ for $10 \mathrm{~min}$; (II) Amplification: 45 cycles of $95^{\circ} \mathrm{C}$ for $10 \mathrm{~s}, 63^{\circ} \mathrm{C}$ for $10 \mathrm{~s}, 72^{\circ} \mathrm{C}$ for $8 \mathrm{~s}$, and $72^{\circ} \mathrm{C}$ for $1 \mathrm{~s}$ (acquisition step). (III) Melt curve analysis: $95^{\circ} \mathrm{C}$ for $10 \mathrm{~s}$, $65^{\circ} \mathrm{C}$ for $10 \mathrm{~s}$, and gradual heating to $97^{\circ} \mathrm{C}$ with continuous fluorescence acquisition. (IV) A final cooling step at $37^{\circ} \mathrm{C}$ was included for handling of the samples, because the LightCycler has no cooling bloc. Analysis of the relative changes was performed using LightCycler480 Software 1.5.0 SP4 (Version 1.5.0.39, Roche). All quantifications were normalized to the level of HPRT gene expression (housekeeping gene). The following primers were used: HPRT forward TCCTCCTCAGACCGCTTTT and reverse CATAACCTGGTTCATCATCGC; IFN $\gamma$ forward TCAAGTGGCATAGATGTGGAAGAA and reverse TGGCTCTGCAGGATTTTCATG; TNF $\alpha$ forward CCACCA CGCTCTTCTGTCTAC and reverse AGGGTCTGGGCCATA GAACT; IL-10 forward GGTTGCCAAGCCTTATCGGA and reverse ACCTGCTCCACTGCCTTGCT; IL-6 forward GAGGATACCACTCCCAACAGACC and reverse AAGTGCA TCATCGTTGTTCATACA; IL-12B forward CATCATCAAA CCAGACCCGCCCAA and reverse AACTTGAGGGAGAA GTAGGAATGG. Primers for iNOS were kindly provided by the group of Microbial Interface Biology.

\section{Multiplex Cytokine Assay}

The concentrations of various cytokines in lung homogenates were determined by LEGENDplex ${ }^{\mathrm{TM}}$ (Mouse $\mathrm{T}$ helper cytokine panel and Mouse Inflammation panel, BioLegend) according to the manufacturer's protocol.

\section{Nitric Oxide Assay}

Nitric oxide was determined in lung homogenates as $\mathrm{NO}_{2}{ }^{-}$using the Griess reagent (Sigma). Samples were mixed in equal volume with Griess reagent and incubated for $15 \mathrm{~min}$. Optical density was measured at $560 \mathrm{~nm}$ with Tecan Sunrise Reader (Magellan).

\section{Isolation of CD11c ${ }^{+}$Cells and M. tuberculosis Infection}

C57BL/6 mice were infected with $1 \times 10^{5}$ iRBC i.p. as described before. Fourteen days p.i. spleens from infected mice and naïve control mice, respectively, were harvested and digested in $100 \mu \mathrm{g} / \mathrm{ml}$ DNase I (Roche) and $50 \mu \mathrm{g} / \mathrm{ml}$ Liberase TL (Roche) in RPMI for $30 \mathrm{~min}$ and passed through a $100 \mu \mathrm{m}$ pore size cell strainer. Remaining erythrocytes were lysed (155 mM NH $4 \mathrm{Cl}, 10 \mathrm{mM} \mathrm{KHCO}_{3}, 0.1 \mathrm{mM}$ EDTA in $\mathrm{H}_{2} \mathrm{O}$ ) and cells were resuspended in RPMI 1640 supplemented with $2 \mathrm{mM}$ L-glutamine, $1 \%$ v/v Hepes, $50 \mu \mathrm{M}$ $\beta$-mercaptoethanol and $10 \% \mathrm{v} / \mathrm{v}$ heat-inactivated fetal calf serum (complete RPMI 1640 medium). Dead cells were removed using the Dead Cell Removal Kit (Miltenyi) according to the manufacturer's instruction. Afterwards, CD11c ${ }^{+}$cells were magnetically labeled and isolated using CD11c MicroBeads (Miltenyi) as recommended by the manufacturer. $2 \times 10^{5}$ CD11c ${ }^{+}$cells were infected with $M$. tuberculosis in a MOI 1 directly from frozen stock. At indicated time points cells were lysed with $0.5 \%(\mathrm{v} / \mathrm{v})$ Triton X-100 in PBS and tenfold serial dilutions of organ homogenates in sterile water/1\% v/v Tween $80 / 1 \% \mathrm{w} / \mathrm{v}$ albumin were plated onto Middlebrook $7 \mathrm{H} 11$ agar plates.

\section{T Cell Proliferation Assay}

$\mathrm{CD}_{11 \mathrm{c}^{+}}$cells isolated as described above were incubated with $100 \mu \mathrm{g} / \mathrm{ml}$ Ovalbumin (Sigma-Aldrich) over night or $1 \mu \mathrm{M}$ OT-II peptide (peptide synthesis, Research Center Borstel) for $3 \mathrm{~h}$. Spleens of transgenic OT-II mice, which contain $\mathrm{CD}^{+} \mathrm{T}$ cells specific for chicken ovalbumin 323339, were harvested, passed through a $100 \mu \mathrm{m}$ pore size cell strainer and erythrocytes were lysed (155 $\mathrm{mM} \mathrm{NH} \mathrm{NH}_{4} \mathrm{Cl}$, $10 \mathrm{mM} \mathrm{KHCO} 3,0.1 \mathrm{mM}$ EDTA in $\mathrm{H}_{2} \mathrm{O}$ ). OT-II CD4 ${ }^{+} \mathrm{T}$ cells were isolated using $\mathrm{CD}^{+}{ }^{+} \mathrm{T}$ cell isolation kit (Miltenyi; untouched) according to the manufacturer's instruction. T cells were further labeled with CFSE (Invitrogen) and $1 \times 10^{5}$ were co-incubated with $1 \times 10^{3} \mathrm{CD}_{11 \mathrm{c}^{+}}$cells for three days at $37^{\circ} \mathrm{C}$.

\section{Statistical Analysis}

Statistical analysis was performed by Mann-Whitney test or by Kruskal-Wallis test followed by Dunn's Multiple Comparison test as described in the figure legends. Correlation between variables was determined by calculating Pearson's coefficient using a 2-tailed analysis. In vitro CFU data were log transformed and analyzed by unpaired student's $t$-test. All data were analyzed using GraphPad Prism 5 (GraphPad Software, Inc.).

\section{RESULTS}

\section{$P$. yoelii Infection Exacerbates Chronic M. tuberculosis Infection}

Due to its immunomodulatory properties we hypothesized that $P$. yoelii co-infection would interfere with immune control of chronic M. tuberculosis infection in C57BL/6 mice. Therefore, mice were infected via the aerosol route with a low dose of M. tuberculosis H37Rv. Thirty days later, when the immune response against $M$. tuberculosis was fully established and $\mathrm{Tb}$ in a chronic state, mice were infected with $1 \times 10^{5}$ $P$. yoelii infected red blood cells (iRBCs) i.p. Parasitemia was monitored every 2-3 days on Giemsa stained thin blood smears starting 4 days after $P$. yoelii infection. Furthermore, anemia was assessed during acute $P$. yoelii infection by measuring hemoglobin levels in the blood. As expected, with rising parasitemia, hemoglobin levels significantly dropped in $P$. yoelii infected animals when compared to animals infected with $M$. tuberculosis (Figures 1A,B). However, we did not detect significant differences in parasitemia, anemia, and weight change between $P$. yoelii singly and co-infected animals (Figures 1A-C). Hence, the course of $P$. yoelii malaria does not change in mice chronically infected with M. tuberculosis. 

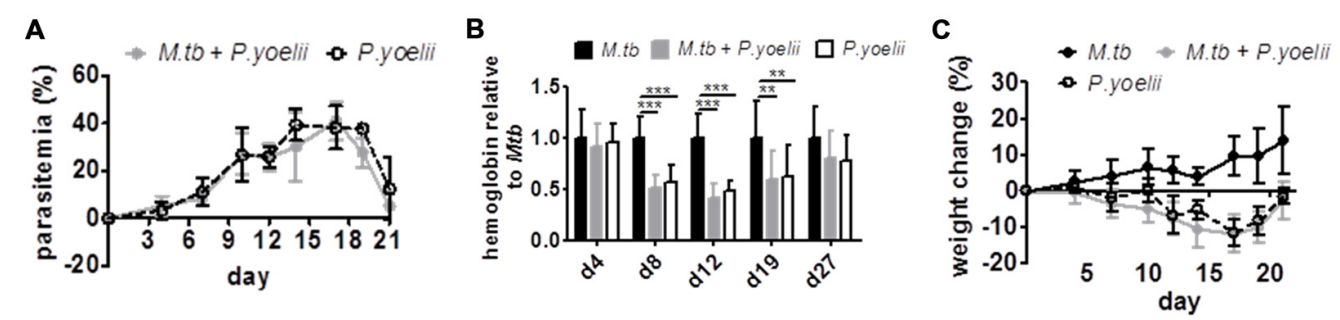

FIGURE 1 | The course of $\boldsymbol{P}$ yoelii infection is unchanged. C57BL/6 mice were infected via the aerosol route with $M$. tuberculosis H37Rv, and 30 days later with $1 \times 10^{5}$ iRBCs i.p. (A,C) Parasitemia and weight were determined every 2-3 days starting 4 days after $P$. yoelii infection (groups of 7-8; one experiment representative out of three). (B) Starting 4 days after $P$. yoelii infection, hemoglobin levels were determined by collecting blood from tail vain, diluting in Drabkin's Solution supplemented with Brij L23 Solution and measured at $540 \mathrm{~nm}$ (groups of 13-24). Statistical analysis was performed using the Kruskal-Wallis test with Dunn's multiple comparison (data represent mean $\pm \mathrm{SD}$ ). ${ }^{* *} p<0.01 ;{ }^{* * *} p<0.001$.

Fifty-one days after M. tuberculosis infection, when P. yoelii infection was almost cleared, mice were sacrificed and lung, spleen, and liver were removed to analyze mycobacterial load. Compared to $M$. tuberculosis only infected mice, co-infected mice presented with a slight but statistically significant increase in M. tuberculosis burden in all three organs (Figures 2A-C). To further evaluate M. tuberculosis loads in the lung tissue, superior lung lobes were paraffin-embedded and sections were acid fast stained to visualize M. tuberculosis. Notably, while single bacteria were found across the M. tuberculosis-infected lungs, coinfected mice frequently harbored large clusters of mycobacteria (Figures 2D, bottom, arrows), indicating that CFU values were most likely underestimating actual $M$. tuberculosis numbers in co-infected lungs. In conclusion, these data suggest that malaria limits control of $M$. tuberculosis.

Mycobacterial infection leads to cellular infiltrations and formation of granulomatous lesions in the lung which are necessary to restrict and control the infection. However, excessive pathology also results in disease exacerbation (O'Garra et al., 2013). To investigate histopathological changes in single- and co-infected lungs, superior lung lobes were paraffin-embedded and $4 \mu \mathrm{m}$ sections were $\mathrm{H} \& \mathrm{E}$ stained. Lungs of co-infected mice displayed increased pulmonary infiltration (Figure 2E) and increased total lung weight compared with lungs of mice infected with M. tuberculosis alone (Figure 2G). This was in line with a significant rise of absolute cell numbers in co-infected lungs compared to those of control animals (Figure 2H). In depth microscopic evaluation of lung sections revealed the deposition of hemozoin (Figure 2F), the malaria pigment which is produced by the parasite during digestion of red blood cell hemoglobin, in lungs of co-infected mice. Moreover, histopathological changes were more pronounced in co-infected lungs as reflected by more granulomatous lesions compared to $M$. tuberculosis infected lungs. Consequently, the total lung area affected was significantly increased upon P. yoelii co-infection compared to M. tuberculosis single infection (Figure 2I).

\section{$P$ yoelii Co-infection Augments Cytokine Responses in the Lung}

The balance of pro- and anti-inflammatory cytokines is necessary to restrict mycobacterial growth as well as to avoid immunopathology and maintain tissue function (O'Garra et al., 2013). To assess the effects of $P$. yoelii co-infection on different pro- and anti-inflammatory cytokines, their expression was determined on RNA and protein level (Figures 3A,B). Overall cytokine responses were elevated in co-infected compared to single infected mice. On mRNA level we found a significant increase in IFN $\gamma$ and IL-10 expression (Figure 3A), whereas on protein level IFN $\gamma$, TNF $\alpha$, IL-6, IL-10, and IL-17A were significantly increased compared to $M$. tuberculosis infected mice (Figure 3B). Correlation analysis revealed that increased TNFa levels positively correlated with increased M. tuberculosis CFU in lungs of co-infected mice $(r=0.81$, Pearson's correlation; Figure 3C). In contrast, elevated IL-10 levels did not correlate with increased CFU in co-infected animals (Figure 3D). IL10 is known to exert anti-inflammatory functions including down-modulation of macrophage effector functions (Gazzinelli et al., 1992; Murray et al., 1997; Murray and Young, 1999). Increased IL-10 expression in co-infection mice thus prompted us to determine inducible nitric oxide synthase (iNOS) expression and NO levels in lung tissue. Neither the mRNA expression of iNOS nor the release of NO was decreased in lungs of co-infected mice suggesting that this host defense mechanism was not impaired during $P$. yoelii co-infection (Figures 3E,F).

\section{T Cell Response is Not Impaired in Co-infected Mice}

Histopathological alterations and elevated numbers of total lung cells together with elevated cytokine levels indicated increased immune cell recruitment and activity in the lungs of co-infected mice. Thus, we investigated the cell-mediated immune responses by flow cytometry. NK cells, defined as $\mathrm{CD}^{-} \mathrm{NK} 1.1^{+}$cells, were significantly decreased in lungs of co-infected compared to M. tuberculosis infected mice (Figure $\mathbf{4 A}$ ). In contrast, the numbers of both $\mathrm{CD}^{+}$and $\mathrm{CD} 4^{+} \mathrm{T}$ cells were significantly increased in the presence of $P$. yoelii (Figure 4B). Further analysis revealed significantly higher frequencies of $\mathrm{CD}^{+}$and $\mathrm{CD}^{+}$effector $\mathrm{T}$ cells $\left(\mathrm{CD} 44^{+} \mathrm{CD}_{22} \mathrm{~L}^{-}\right)$in co-infected lungs which produced significantly more cytokines upon ex vivo re-stimulation with $\alpha \mathrm{CD} 3 / \alpha \mathrm{CD} 28$ (Figures $4 \mathrm{C}-\mathrm{E}$ ). Moreover, 


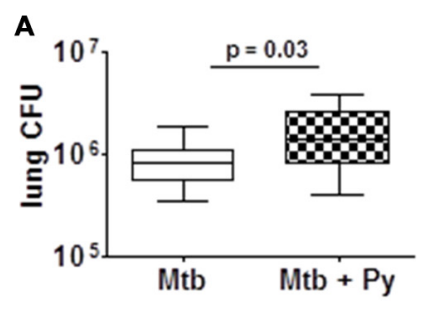

D

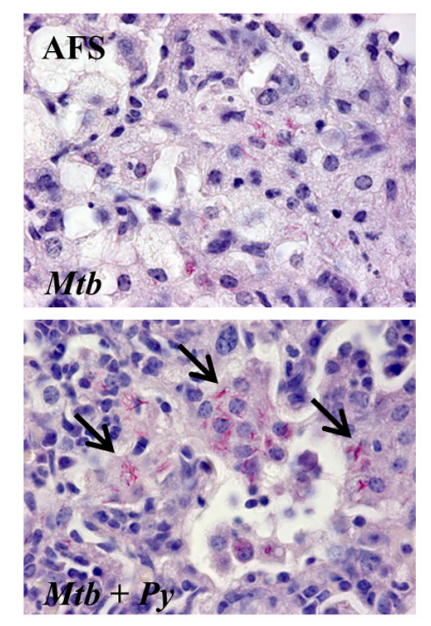

B

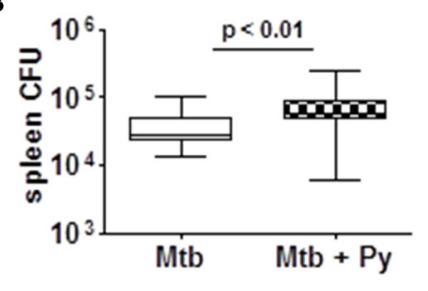

E

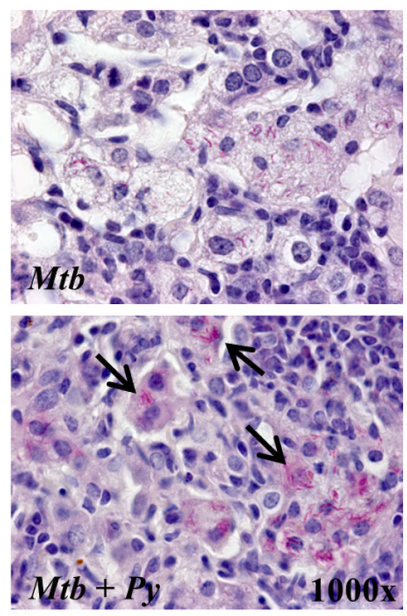

C

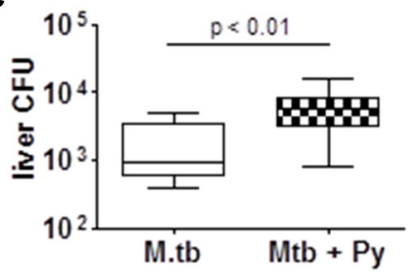

$\mathbf{F}$
G

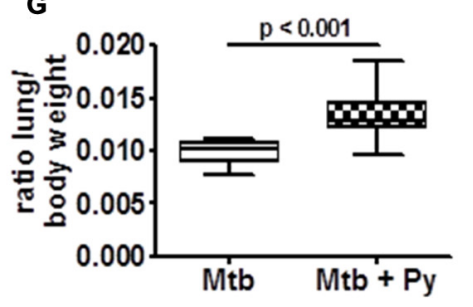

H

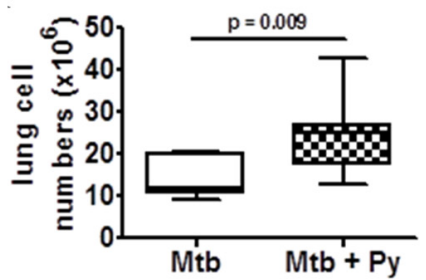

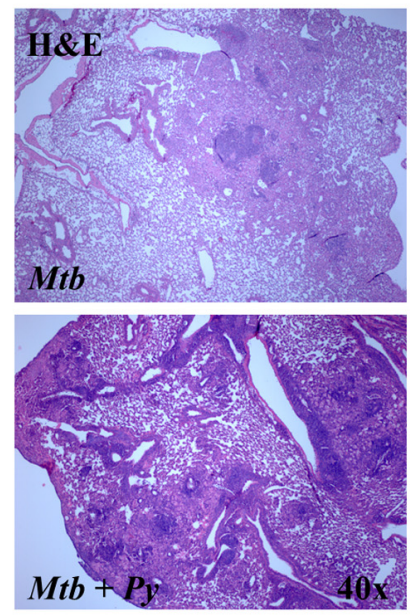

I

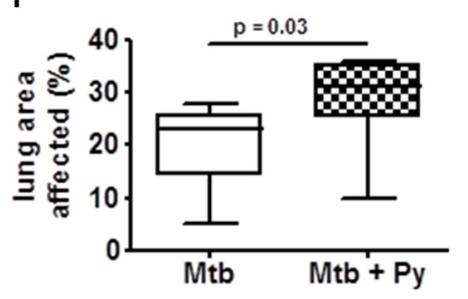

FIGURE $2 \mid \boldsymbol{P}$. yoelii co-infection leads to increased lung pathology and $\boldsymbol{M}$. tuberculosis burden. C57BL/6 mice were infected via the aerosol route with M. tuberculosis H37Rv, and 30 days later with $1 \times 10^{5}$ iRBCs i.p. Mice were sacrificed 21 days after $P$. yoelii infection for CFU determination in lung, spleen, and liver (A-C; lung and spleen groups of 16-23, liver groups of 9-15; data pooled from 2 to 3 independent experiments). Superior lung lobes were paraffin-embedded and $4 \mu \mathrm{m}$ sections were acid fast and H\&E stained to visualize M. tuberculosis (D) and hemozoin distribution (F; dark brown pigment) and to assess pulmonary inflammation (E). Arrows indicate mycobacterial clusters. One or two representative images per group are shown $(n=7-8)$. (G) Lung to body weight ratio was determined in two independent experiments $(n=9-15)$. (H) Total lung cell numbers $(n=7-8)$. (I) Total area occupied by inflammatory lesions per lobe was quantified using cell'B software $(n=7-8)$. Data are shown as box and whisker plots with the median and analyzed statistically using the Mann-Whitney test (A-C, G-I).

multifunctional $\mathrm{CD}^{+} \mathrm{T}$ cells, which have been associated with protection against $\mathrm{Tb}$ (Forbes et al., 2008) and secrete IFN $\gamma, \mathrm{TNF} \alpha$, and IL-2, were also significantly increased in the lungs of co-infected mice compared to $M$. tuberculosis mice (Figure 4F).

As the spleen plays a pivotal role in the development of the immune response against Plasmodium infection and in elimination of iRBC, we studied the cell-mediated immune response in this organ by flow cytometry. The overall number of splenocytes was significantly increased during co-infection (Figure 4G), reflecting splenomegaly associated with $P$. yoelii infection. As in the lung, NK cell numbers were significantly decreased in co-infected compared to M. tuberculosis infected mice (Figure $\mathbf{4 H}$ ). There was no difference in the numbers of both splenic $\mathrm{CD}^{+}$and $\mathrm{CD}^{+}{ }^{+} \mathrm{T}$ cells between co-infected and M. tuberculosis infected mice (Figure 4I). Although frequencies of effector $\mathrm{CD}^{+}$and $\mathrm{CD}^{+}{ }^{-} \mathrm{T}$ cells $\left(\mathrm{CD} 44^{+} \mathrm{CD}^{-} \mathrm{L}^{-}\right)$were significantly higher in co-infected spleens they did not produce more cytokines upon ex vivo re-stimulation with $\alpha \mathrm{CD} 3 / \alpha \mathrm{CD} 28$ (Figures 4J-L) compared to splenic T cells from M. tuberculosis infected mice. Solely, the production of IL-10 was significantly increased.

In conclusion, while NK cell numbers were significantly decreased in lungs and spleens, $\mathrm{T}$ cell frequencies and function were increased in lungs when $P$. yoelii was concurrent with M. tuberculosis. 


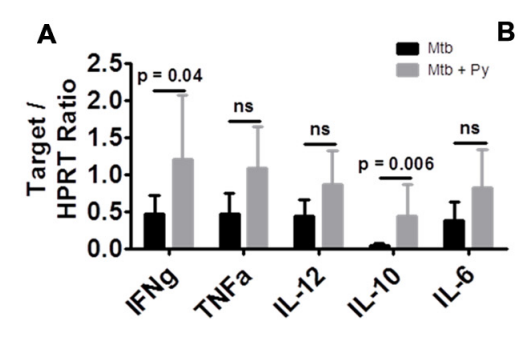

C

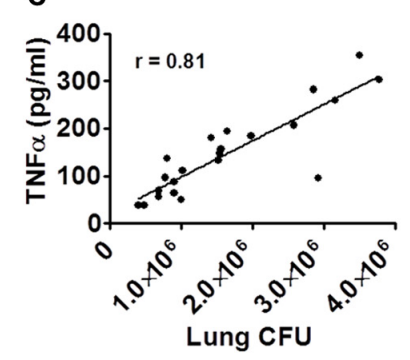

D
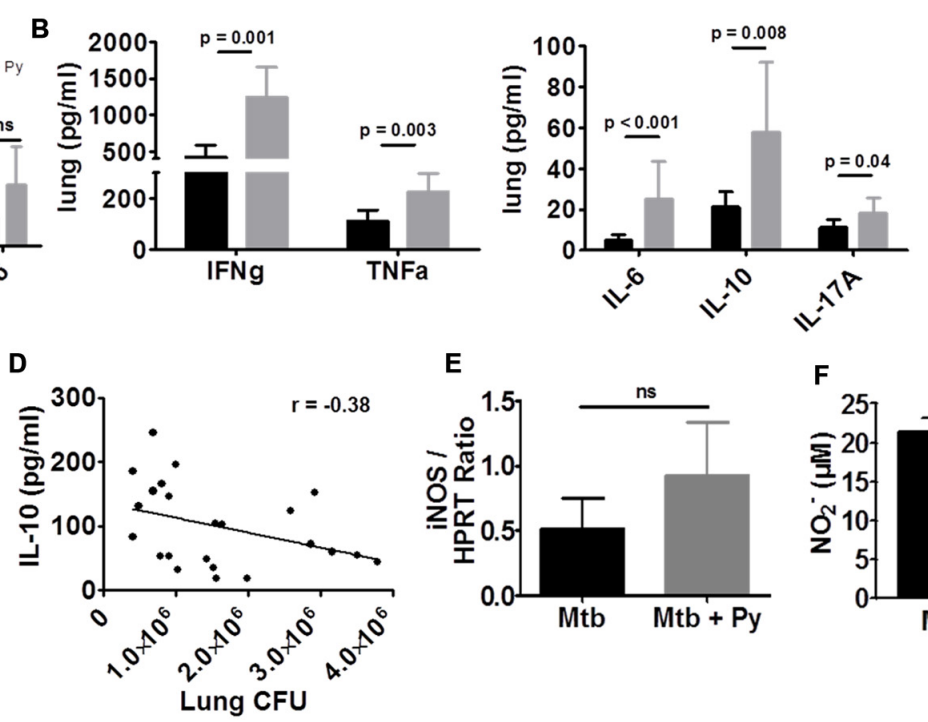

E
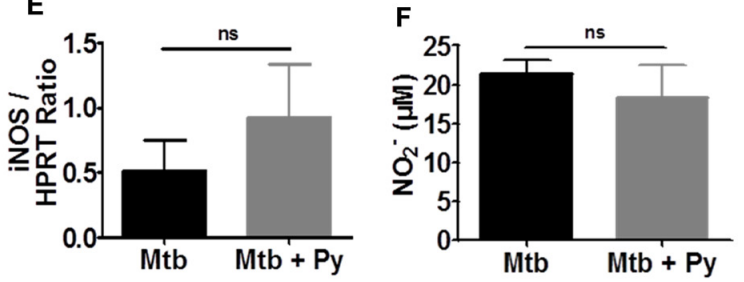

FIGURE 3 | P. yoelii co-infection augments cytokine responses in the lung. C57BL/6 mice were infected via the aerosol route with M. tuberculosis H37Rv, and 30 days later with $1 \times 10^{5}$ iRBCs i.p. Lungs were collected 21 days after $P$. yoelii infection for analysis of cytokine (A) or iNOS (E) expression by quantitative RT-PCR (expression relative to housekeeping gene HPRT). (B) Cytokine protein levels were measured in lung lysates in M. tuberculosis and co-infected mice using LEGENDplex. (F) Nitric oxide production was determined by Griess reagent in lung lysates. Data represent one experiment representative for 2-3 independent ones and are shown as mean \pm SD ( $n=5-10$; Mann-Whitney test). (C) TNF $\alpha$ and (D) IL-10 protein levels were correlated to lung CFU using Pearson's correlation.

\section{CD11c ${ }^{+}$Cells are Induced by $P$ yoelii Co-infection and Promote Survival of M. tuberculosis In Vitro}

We next studied the influence of co-infection on the innate immune compartment of the lung via flow cytometry. We could observe a slight but not significant increase in CD $45^{+}$CD 19 ${ }^{-}$Ly6G $^{\text {high }}$ CD $11 b^{\text {high }}$ cells (Figure 5A) indicating that neutrophils did not contribute to increased cellular infiltration in lungs from co-infected mice. In contrast, we found significantly more CD $45^{+} \mathrm{CD} 19^{-} \mathrm{Ly}_{6 \mathrm{G}}{ }^{-} \mathrm{CD} 11 \mathrm{~b}^{-} \mathrm{CD} 11 \mathrm{c}^{+}$ cells in lungs from co-infected compared to $M$. tuberculosis infected mice (Figure 5B). This was even more pronounced in the spleen (Figure 5C). The pulmonary $\mathrm{CD}_{11} \mathrm{~b}^{-} \mathrm{CD} 11 \mathrm{c}^{+}$ compartment could be further divided into CD11chigh and CD11c ${ }^{\text {int }}$ cells (Figure 5D). While the CD11 $c^{\text {high }}$ population remained unchanged during co-infection, the frequency of CD11 $c^{\text {int }}$ cells significantly increased in the presence of $P$. yoelii (Figure 5E). Analysis of co-stimulatory molecules revealed reduced surface expression of CD86 on CD11c int cells from co-infected as compared to $M$. tuberculosis infected mice (Figures 5F,G). Likewise, CD11 $c^{\text {high }}$ cells, although unchanged in numbers, exhibited a significant although less prominent reduction in the expression of CD86 (Figure 5H). When we evaluated both populations for their forward (FSC-A) and side scatter (SSC-A) pattern, CD11 $c^{\text {int }}$ cells were FSC-A ${ }^{\text {low }} / S S C-A^{\text {low }}$ while CD11 $\mathrm{c}^{\text {high }}$ cells were FSC-A $\mathrm{A}^{\text {low }} / \mathrm{SSC}-\mathrm{A}^{\text {high }}$, indicating increased granularity of $\mathrm{CD} 11 \mathrm{c}^{\text {high }}$ cells compared with CD11 $c^{\text {int }}$ cells (Figure 5I). Alterations in leukocyte recruitment in co-infected mice prompted us to investigate chemokine protein levels in lung tissue. We found significantly elevated concentrations of monocyte chemoattractant protein-1 (MCP-1), one of the key chemokines that regulate migration and infiltration of monocytes/macrophages and dendritic cells (DCs; Figure 5J). Together, our data indicate that $P$. yoelii co-infection induces the overproduction of MCP-1 and the recruitment of CD11b-CD11 ${ }^{\text {int }}$ cells to the lungs of $M$. tuberculosis infected mice.

Plasmodium infection is known to modulate the function of phagocytic cells (Ocana-Morgner et al., 2003; Orengo et al., 2008; Hawkes et al., 2010), which is also indicated by the down-regulation of CD86 expression on $\mathrm{CD}_{11}{ }^{+}$cells from co-infected mice shown herein. To further analyze the function of malaria-induced $\mathrm{CD}_{11}{ }^{+}$cells, we investigated their ability to stimulate $\mathrm{T}$ cell proliferation in vitro. To do so, C57BL/6 mice were infected with $P$. yoelii and 14 days p.i. when parasitemia peaks (Figure 1A), CD11c ${ }^{+}$DCs were isolated from spleens of infected and naïve control mice using magnetically labeled beads. Subsequently, isolated DCs were loaded with the model antigen ovalbumin (Ova) or Ovaderived peptides and co-cultured with CFSE-labeled transgenic OT-II T cells for 3 days. DCs from naïve and $P$. yoelii infected spleens were able to induce $\mathrm{T}$ cell proliferation equally well (Figure 5K), indicating that DCs from malariainfected mice are fully functional antigen presenting cells. We next infected DCs from naïve or malaria infected mice with M. tuberculosis (MOI 1) and monitored intracellular survival over time. Noteworthy, while DCs from naïve animals were able to restrict $M$. tuberculosis survival $\mathrm{CD}_{11}{ }^{+} \mathrm{DCs}$ from $P$. yoelii infected mice supported $M$. tuberculosis survival and growth, resulting in a $1.5 \mathrm{log}$ difference in CFU after 6 days (Figure 5L). 

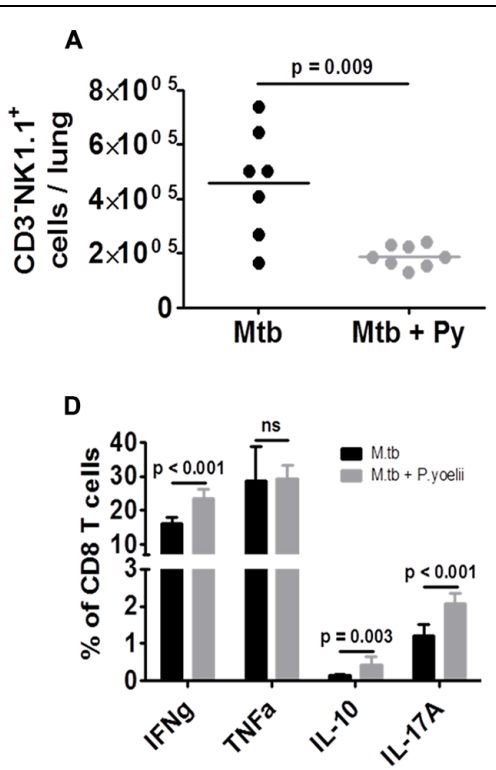

$\mathbf{G}$
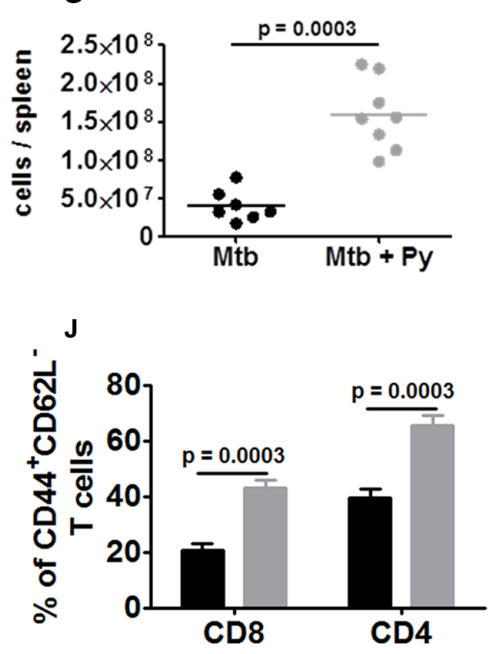

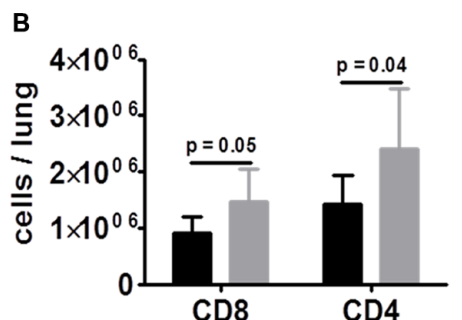

E

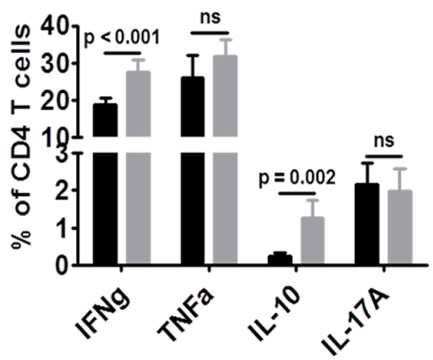

H

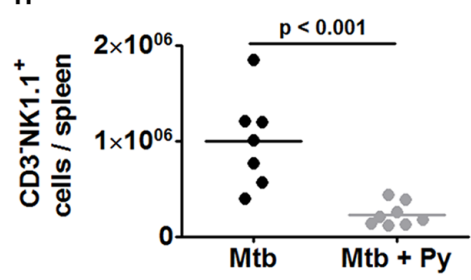

$\mathbf{K}$

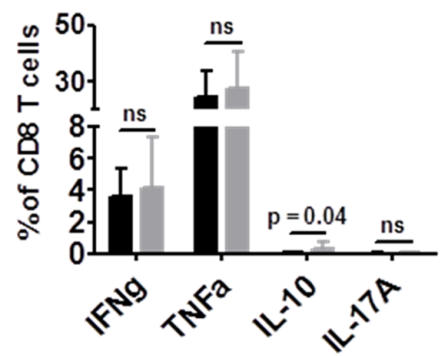

C

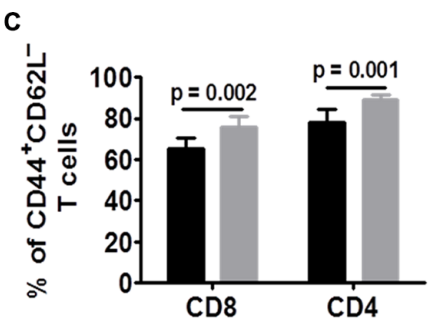

$\mathbf{F}$
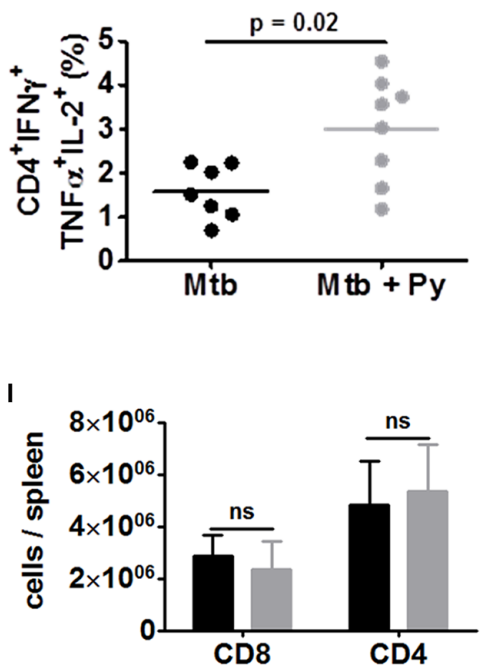

$\mathbf{L}$

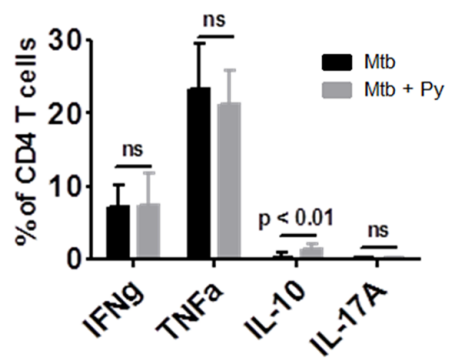

FIGURE 4 | T cell responses are not impaired in co-infected mice. C57BL/6 mice were infected via the aerosol route with $M$. tuberculosis H37Rv, and 30 days later with $1 \times 10^{5}$ iRBCs i.p. Lungs were collected 21 days after $P$. yoelii infection and single cell suspensions were analyzed for the presence and activation status of NK cells, $\mathrm{CD}^{+}$and $\mathrm{CD}^{+} \mathrm{T}$ cells by flow cytometry. (A) Lung cells were analyzed for CD3- NK1.1 ${ }^{+}$and (B) gated on CD90.2 to determine the total numbers of $\mathrm{CD}^{+}$and $\mathrm{CD}^{+}{ }^{+} \mathrm{T}$ cells as well as $\mathbf{( C )}$ the proportion of effector T cells (CD44+ $\left.{ }^{+} \mathrm{CD}_{2} \mathrm{~L}^{-}\right)$. (D-F) Lung cells were restimulated ex vivo with $\alpha \mathrm{CD} 3 / \alpha \mathrm{CD} 28(5 \mu \mathrm{g}$, respectively) and analyzed by flow cytometry for the presence of IFN $\gamma$, TNF $\alpha$, IL-10, IL-17A, and IFN $\gamma / T N F \alpha / I L-2$ producing CD4+ and CD8 ${ }^{+}$T cells. (G) Total spleen

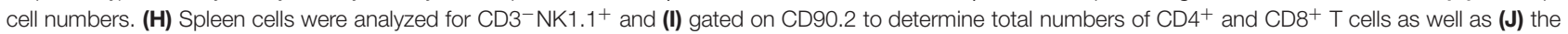
proportion of effector T cells (CD44 $\left.{ }^{+} \mathrm{CD}_{2} \mathrm{~L}^{-}\right)$. (K,L) Spleen cells were restimulated ex vivo with $\alpha \mathrm{CD} 3 / \alpha \mathrm{CD} 28$ (5 $\mu \mathrm{g}$, respectively) and analyzed by flow cytometry for the presence of IFN $\gamma$, TNF $\alpha$, IL-10, and IL-17A. Symbols and bars represent individual mice or means \pm SD, respectively ( $n=7-8$; Mann-Whitney test). For full gating strategies, see Supplementary Figures S1A-C.

In conclusion, $P$. yoelii co-infection induces an increase in CD11c ${ }^{+}$cells in lungs and spleens which support the growth of M. tuberculosis in vitro.

\section{$P$. yoelii Induced Exacerbation of Tb Disease is Transient}

Exacerbated lung pathology together with elevated M. tuberculosis burden in lung, spleen, and liver in co-infected mice prompted us to analyze the long-term consequences of $P$. yoelii co-infection. To do so, mice were sacrificed 200 days after $M$. tuberculosis infection (170 days after P. yoelii infection). While regression of splenomegaly was observed in mice infected with $P$. yoelii alone spleens of co-infected mice were still enlarged. Likewise, spleens and livers of co-infected mice showed darker pigmentation resulting from the accumulation of hemozoin produced by the parasite during digestion of red 


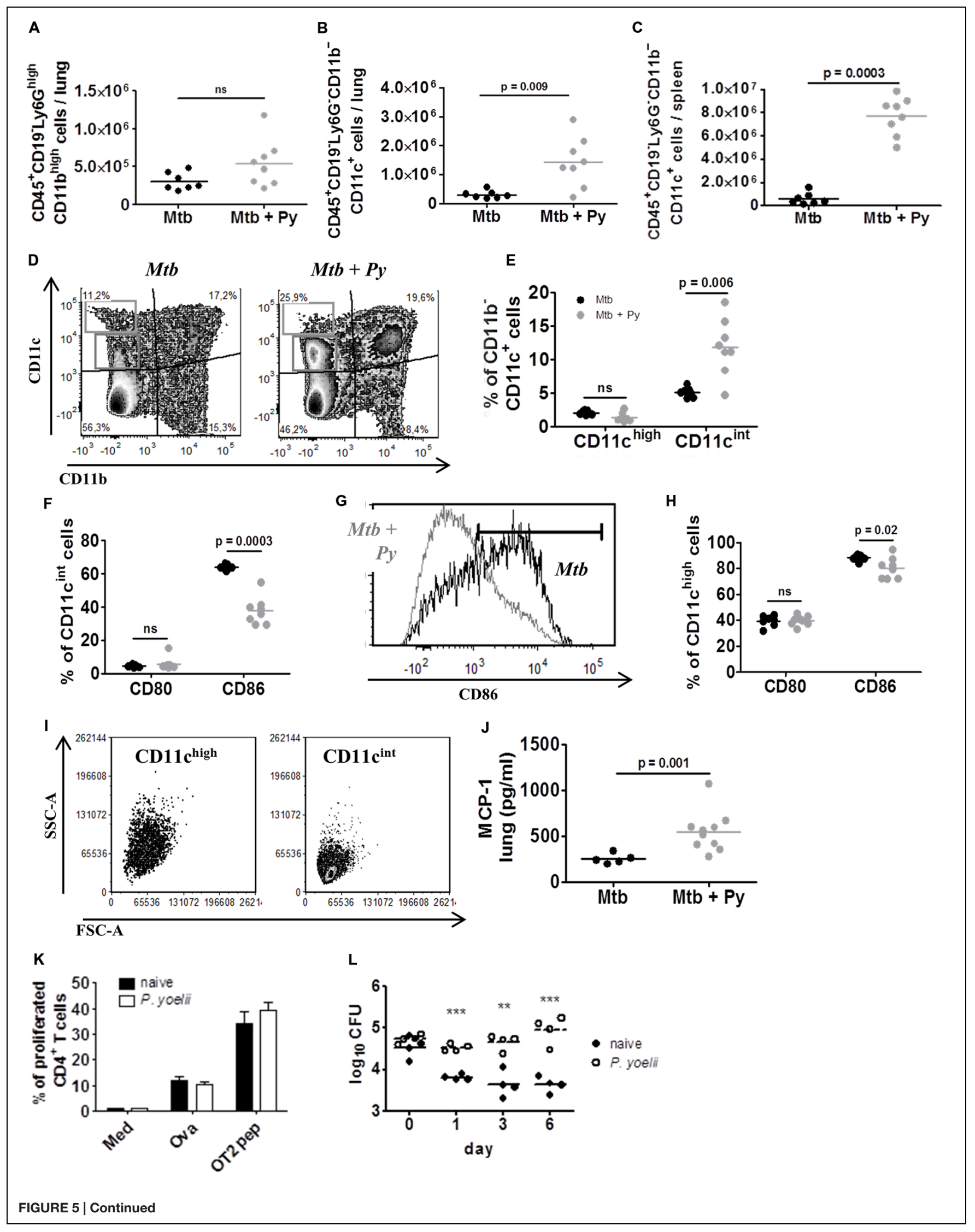




\section{FIGURE 5 | Continued}

CD11c $^{+}$cells are induced by $\boldsymbol{P}$ yoelii co-infection and promote survival of $\boldsymbol{M}$. tuberculosis in vitro. C57Bᄂ/6 mice were infected via the aerosol route with M. tuberculosis H37Rv, and 30 days later with $1 \times 10^{5}$ iRBCs i.p. Lungs and spleens were collected 21 days after $P$. yoelii infection and single cell suspensions were analyzed for the presence and activation status of $\mathrm{Ly}_{6 \mathrm{G}^{+}}$and $\mathrm{CD} 11 \mathrm{C}^{+}$cells by flow cytometry. (A) Lung cells were gated on CD45 ${ }^{+}$and further on CD19- cells and analyzed for the presence of Ly6G ${ }^{\text {high }} \mathrm{CD} 11 \mathrm{~b}^{\text {high }}$ neutrophils. Symbols and bars represent individual mice and means, respectively (groups of 7-8). (B) Lung and (C) spleen cells were gated on CD45 ${ }^{+}$and further on CD19 ${ }^{-}$and $\mathrm{Ly}_{6 G^{-}}$cells and analyzed for the presence of CD11 b ${ }^{+}$and CD11 $\mathrm{C}^{+}$cells. (D-H) Pulmonary

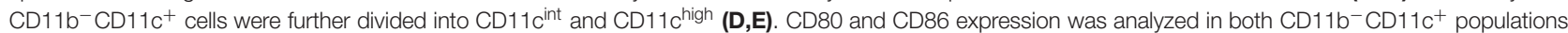
(F-H). CD11 $\mathrm{C}^{\text {int }}$ and CD11 $\mathrm{C}^{\text {high }}$ populations were characterized in size (FSC-A) and granularity (SSC-A) (I). Symbols and bars represent individual mice and means, respectively ( $n=7-8$; Mann-Whitney test). For full gating strategy, see Supplementary Figure S1D. (J) MCP-1 protein level was measured in lung lysates in M. tuberculosis and co-infected mice using LEGENDplex. (K,L) C57BL/6 mice were infected with P. yoelii and 14 days p.i., CD11 ${ }^{+}$cells were isolated from spleens of infected and naïve control mice using magnetically labeled beads. Isolated CD11 ${ }^{+}$cells were loaded with the model antigen Ova or Ova-derived peptides and co-cultured with CFSE-labeled transgenic OT-II T cells for 3 days. Loss of CFSE as indicator for T cell proliferation was measured by flow cytometry (K; performed in triplicates). In addition, isolated $\mathrm{CD}_{11 \mathrm{C}^{+}}$cells from naïve or malaria infected mice were infected with $\mathrm{M}$. tuberculosis (MOI 1) and plated on $7 \mathrm{H} 11$ agar plates at indicated time points (L, one representative experiment out of three). Symbols and bars represent individual mice and means \pm SD, respectively. Unpaired student's t-test. ${ }^{* *} p<0.01,{ }^{* * *} p<0.001$.

blood cell hemoglobin while pigmentation was very much reduced in $P$. yoelii singly infected mice (data not shown). These observations indicate that the full resolution of malariarelated syndromes was delayed in $M$. tuberculosis infected mice.

Determination of mycobacterial CFU revealed that co-infected mice still presented with a statistically significant but slight increase in $M$. tuberculosis burden in the lung, but not in the spleen (Figure 6A). Microscopic evaluation of lung sections revealed no differences in histopathology between $M$. tuberculosis singly and co-infected mice (Figure 6B). Inflammation had progressed over time, affecting approximately half of the lung area of mice from both groups (Figure 6C). In line with the only slightly increased M. tuberculosis burden and comparable histopathological changes in the lungs, mice from both groups had survived until this time-point of analysis without any clinical signs of disease.

In good agreement with histological observations, we could no longer observe differences in inflammatory immune responses in the lungs between both groups. Comparable numbers of $\mathrm{CD}^{+}$and $\mathrm{CD}^{+}{ }^{+} \mathrm{T}$ cells were recovered from M. tuberculosis or co-infected lungs, which produced comparable amounts of cytokines upon ex vivo re-stimulation with $\alpha \mathrm{CD} 3 / \alpha \mathrm{CD} 28$ (Figures 6D,E). Accordingly, cytokine levels in lung homogenates were no longer increased in co-infected mice. In contrast, levels of TNF $\alpha$, IL-6, IL-10, and IL-17A were significantly decreased in co-infected lungs (Figure 6F). Likewise, numbers of $\mathrm{CD}_{4} 5^{+} \mathrm{CD} 19^{-} \mathrm{Ly}_{6 \mathrm{G}^{-}} \mathrm{CD}_{11 \mathrm{~b}}{ }^{-} \mathrm{CD} 11 \mathrm{c}^{+}$ cells were no longer elevated in lungs from co-infected compared to $M$. tuberculosis-infected mice (Figure 6G). The same was true for both $\mathrm{CD} 11 c^{\text {high }}$ and $\mathrm{CD} 11 c^{\text {int }}$ populations (Figure 6H). Moreover, reduced expression of CD86 on both CD11c high and CD11c int cells as observed 21 days after coinfection was no longer apparent at this late time-point (Figures 6I,J).

In conclusion, while the resolution of splenomegaly and clearance of hemozoin was delayed in co-infected mice, one episode of $P$. yoelii co-infection had no long-term consequences on disease progression and survival of M. tuberculosis infected mice.

\section{DISCUSSION}

Malaria and $\mathrm{Tb}$ are co-endemic in many regions in the world, however, compared to other co-infections like $\mathrm{HIV} / \mathrm{Tb}$ or helminth/Tb, it has been given less attention both in clinical and immunological studies. Due to the lack of sufficient human data, the impact of malaria on $\mathrm{Tb}$ and vice versa is difficult to estimate but co-infections are likely to occur very frequently (Bates et al., 2015).

In this study, we demonstrate that co-infection with the self-resolving parasite $P$. yoelii can transiently exacerbate $\mathrm{Tb}$ disease severity although the effect on $M$. tuberculosis control was minimal as reflected by a moderate but nevertheless statistically significant increase in CFU recovered from lung, spleen, and liver of co-infected mice. It should, however, be noted that acid fast staining of tissue sections revealed mycobacterial aggregates in co-infected but rarely in singly infected lungs. Such aggregates were most likely incompletely resolved during organ homogenization and plating, indicating that CFU values were probably underestimating actual $M$. tuberculosis numbers in co-infected lungs (Lewin et al., 2003).

$P$. yoelii infection during chronic $\mathrm{Tb}$ mediated increased recruitment of immune cells to the lungs which coincided with enhanced production of pro- and anti-inflammatory cytokines. T cell responses were not impaired by co-infection but augmented. Upon ex vivo re-stimulation, $\mathrm{CD}^{+}$and $\mathrm{CD}^{+} \mathrm{T}$ cells from co-infected lungs produced more IFN $\gamma$ and IL-10. IL-10 is a negative regulator of Th1 responses and of central importance in immunity to malaria, where it ameliorates immunopathology at the expense of parasite elimination (Couper et al., 2008a,b; Freitas do Rosario et al., 2012). Likewise, IL-10 antagonizes pro-inflammatory responses essential for protective immunity to M. tuberculosis (Murray et al., 1997; Murray and Young, 1999; Boussiotis et al., 2000; Schreiber et al., 2009; Redford et al., 2010) including IFN $\gamma$ induced production of reactive nitrogen intermediates (RNI; Gazzinelli et al., 1992) which mediate the killing of M. tuberculosis (Chan et al., 1992; MacMicking et al., 1997; Herbst et al., 2011). However, iNOS expression and NO levels in lungs were not altered by $P$. yoelii co-infection, which might be one reason why $M$. tuberculosis control was only slightly impaired in co-infected mice. The importance of 
iNOS goes beyond direct killing of $M$. tuberculosis by RNI. During persistent infection, it is indispensable for modulating destructive inflammatory responses and its absence results in increased neutrophil recruitment and tissue necrosis at the site of M. tuberculosis infection (Chan et al., 1995; Cooper et al., 2000; Beisiegel et al., 2009; Mishra et al., 2013). In line with unchanged iNOS expression and despite an increase in IL-17A protein, which is known to induce neutrophil recruitment, we did not observe more neutrophils in co-infected lungs. Our data thus indicate that exacerbated immunopathology in the presence of $P$. yoelii was not neutrophil driven. The significant increase in IFN $\gamma$ in co-infected lungs most likely contributes to the inhibition of pathogenic neutrophil accumulation (Nandi and Behar, 2011). IFN $\gamma$ not only regulates the production of IL17-induced chemokines, such as KC or MIP-2 but it suppresses expression of E- and P-selectin on endothelial cells which are important for neutrophil trafficking into inflamed tissue (Melrose et al., 1998; Desvignes and Ernst, 2009). Moreover, IFN $\gamma$ can act on neutrophils directly by accelerating neutrophil death in vitro (Nandi and Behar, 2011). The source for IFN $\gamma$ were most likely $\mathrm{T}$ cells, since NK cells, which contribute to early IFN $\gamma$ production during M. tuberculosis infection (Korbel et al., 2008), were significantly decreased in numbers during co-infection. Depletion of NK cells prior to and during infection has no

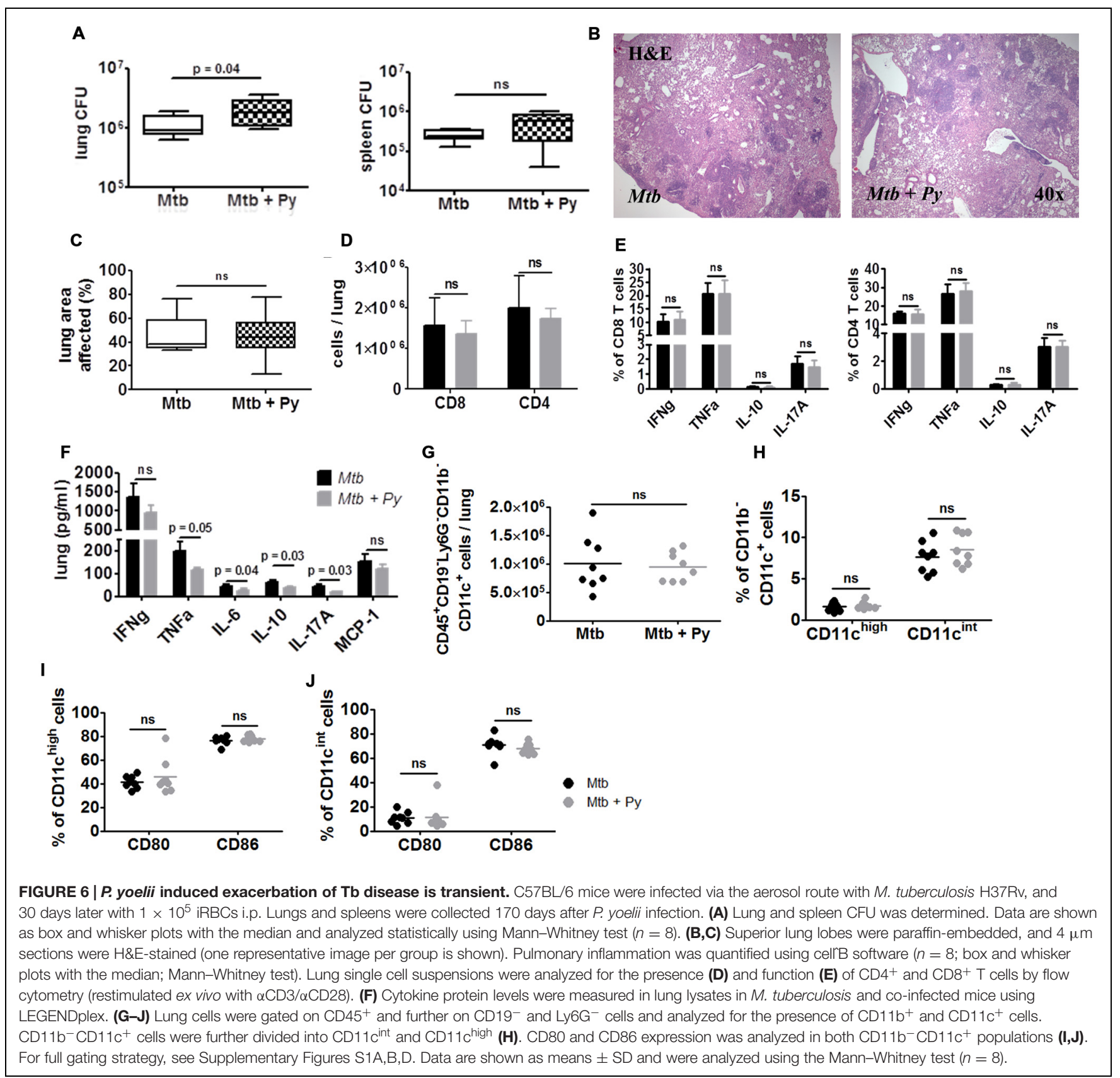


impact on control of mycobacterial growth (Junqueira-Kipnis et al., 2003). Only when T cells are lacking, NK cells can provide protection against $M$. tuberculosis infection to a certain extent and are crucial for the limitation of pathology (Feng et al., 2006). Because IFN $\gamma$ levels were increased and $\mathrm{T}$ cell responses not impaired during $P$. yoelii co-infection, we reasoned that the reduction in NK cell numbers had no consequences on disease outcome.

Resolution of acute infections such as malaria relies on the stimulation of myelopoiesis in order to meet the need for an efficient innate immune response (Belyaev et al., 2013). During blood-stage malaria infection, innate cells such as monocytes, macrophages, and DCs are required in high numbers for the removal of parasitized red blood cells and $\mathrm{T}$ cell priming which takes place in the spleen (Langhorne et al., 2004, 2008; Voisine et al., 2010). Of these innate cells, CD11c ${ }^{+}$DCs are involved in both the priming of $\mathrm{T}$ cells and the control of parasitemia (deWalick et al., 2007; Wykes et al., 2007; Voisine et al., 2010). Consequently, it was reported that numbers of CD11 $\mathrm{c}^{+}$DCs in the spleen rise considerably during infection with $P$. yoelii and other rodent malaria parasites (Langhorne et al., 2004; Wykes et al., 2007; Voisine et al., 2010). We found increased numbers of $\mathrm{CD} 1 \mathrm{~b}^{-} \mathrm{CD} 11 \mathrm{c}^{+}$cells in lungs and spleens of co-infected mice compared to mice infected with $M$. tuberculosis alone. While most $\mathrm{CD} 11 \mathrm{c}^{+}$cells represent conventional DCs (cDCs) in the spleen, the classification is more complicated in the lungs were alveolar macrophages also express CD11c (Lancelin and Guerrero-Plata, 2011; Kopf et al.,

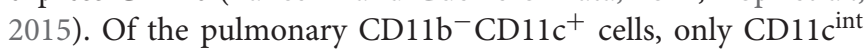
cells were significantly increased during co-infection while numbers of $\mathrm{CD} 11 \mathrm{c}^{\text {high }}$ cells remained unchanged. According to their FSC-SSC pattern, we reasoned these cells are of DC-like nature as reflected by low granularity compared to the $\mathrm{CD} 11 \mathrm{c}^{\mathrm{ci}}$ population which most likely represents alveolar macrophages. Both $\mathrm{CD} 11 \mathrm{c}^{\text {high }}$ and $\mathrm{CD} 11^{\text {int }}$ cells displayed a significant reduction in CD86 surface expression in coinfected compared to those from $M$. tuberculosis infected mice, indicating that $P$. yoelii co-infection interfered with cell activation. This has been described before (Ocana-Morgner et al., 2003; Urban and Todryk, 2006; Orengo et al., 2008). Regardless, $\mathrm{T}$ cell responses were not impaired in co-infected animals. M. tuberculosis specific immune responses are primed by DCs in the lung-draining lymph node in the first 2 weeks of M. tuberculosis infection (Wolf et al., 2008). Thus, by the time of $P$. yoelii co-infection (30 days after M. tuberculosis infection), $M$. tuberculosis specific immune responses were already established.

Beside their role in $\mathrm{T}$ cell priming, DCs along with other phagocytes serve as host cell for M. tuberculosis in lungs of infected mice (Wolf et al., 2007). While activated macrophages are able to kill mycobacteria, DCs fail to eliminate them but rather promote their survival (Bodnar et al., 2001). In fact, when DC numbers were increased by treatment with polyethylene glycol-conjugated GM-CSF or Flt3-L in mice infected with $M$. tuberculosis the overall control of infection was impaired and mice had greater bacterial burden and mortality than controls (Alaniz et al., 2004). In the same study, the control of Listeria was also impaired by the induction of DCs which were shown to harbor viable bacteria. Likewise, Salmonella preferentially infect DCs which are unable to kill them (Marriott et al., 1999). The fact that DCs are less efficient killers than macrophages and more resistant to cytotoxic $\mathrm{T}$ cell lysis (Medema et al., 2001) makes them an attractive cellular niche for intracellular bacteria such as M. tuberculosis. Importantly, DCs from $P$. yoelii infected mice were much more permissive to $M$. tuberculosis survival and replication in vitro than DCs from naïve mice. These results suggest that $P$. yoelii induced DCs provide an environment in which intracellular M. tuberculosis thrive. The induction of an M. tuberculosispermissive monocyte population has been recently reported in a study investigating the consequences of intranasal Poly-IC treatment of M. tuberculosis infected mice (Antonelli et al., 2010). Poly-IC, a synthetic analog of dsRNA, is a potent inducer of type I IFN responses and currently used in clinical trials due to its efficacy in viral infections and malignancies (Borden et al., 2007). Poly-IC treatment triggered the IFN-dependent pulmonary recruitment of a $\mathrm{CD} 11 \mathrm{~b}^{+} \mathrm{F} 4 / 80^{+} \mathrm{Gr} 1^{\text {int }}$ population that displayed enhanced mycobacterial levels. The authors suggest that Poly-IC treatment can detrimentally affect the outcome of $M$. tuberculosis infection by promoting the accumulation of a permissive myeloid population in the lung.

In addition to promoting $M$. tuberculosis survival, infected DCs can shape tissue pathology. Recently $M$. tuberculosis infected inflammatory DCs were shown to spread granulomatous inflammation in infected tissue. $\mathrm{CD} 11 \mathrm{c}^{+} \mathrm{DCs}$ left mycobacterial granulomas with bacteria and formed contact with M. tuberculosis specific $\mathrm{T}$ cells, thereby inducing new multifocal lesions in the lungs (Harding et al., 2015). In our model, $P$. yoelii co-infection induced the recruitment of $\mathrm{CD} 11 \mathrm{c}^{+}$cells to $M$. tuberculosis infected lungs and the formation of more granulomatous lesions as compared to animals infected with M. tuberculosis alone. Thus, increased numbers of $\mathrm{CD} 11 \mathrm{c}^{+}$ cells in co-infected lungs could promote dissemination of mycobacteria across the lungs and the formation of new lesions, thereby contributing to the exacerbated tissue pathology observed herein.

We believe that in our co-infection model, the stimulation of myelopoiesis together with the enhanced recruitment of myeloid progenitors from the bone marrow in the course of $P$. yoelii co-infection results in the enhanced recruitment of immune cells to the site of $M$. tuberculosis infection in the lung, most likely attracted by chemokines which are produced in response to $M$. tuberculosis infection. It has been shown that systemic IFN $\gamma$ responses triggered the secretion of CCL2 (MCP-1) and CCL7 which led to the egress of early myeloid progenitors from the bone marrow during malaria infection (Belyaev et al., 2013). Significantly elevated levels of IFN $\gamma$ and MCP-1 in lungs of co-infected mice could be responsible for enhanced pulmonary recruitment of myeloid cells. In addition, $\mathrm{TNF} \alpha$ directly effects immune cell recruitment by upregulation of endothelial adhesion molecules (Zhou et al., 2007) and induction of chemokine production which further recruit leukocytes to the site of infection (Roach et al., 2002; Algood et al., 2005). 
The deposition of hemozoin, the malaria pigment which is produced by the parasite during digestion of red blood cell hemoglobin, might also augment inflammatory responses in the lung of co-infected mice (Parroche et al., 2007; Deroost et al., 2013). During malaria infection, circulating and resident phagocytes take up and accumulate hemozoin, which is released into the circulation during erythrocyte lysis. This leads to accumulation of malaria pigment in different organs with potential immune modulating consequences. Moreover, some parasites including $P$. falciparum and the rodent strains $P$. berghei and $P$. chabaudi are known to sequester in host tissue with the lung being a major site of parasite sequestration while spleen and liver function in digestion of infected erythrocytes. Infection with the lethal strain $P$. berghei NK65 ( $P b$ NK65) induces severe lung pathology and was described as a model for malaria-associated acute respiratory distress syndrome in mice (MA-ARDS; Van den Steen et al., 2010). Recently, an association has been found between increased levels of hemozoin in pulmonary tissue of $P b$ NK65 infected mice and MA-ARDS (Deroost et al., 2013). This severe lung pathology could be one reason why in $M$. tuberculosis infected mice, the consequences of $\mathrm{P} b \mathrm{NK} 65$ co-infection are much more severe as compared to $P$. yoelii co-infection (Mueller et al., 2012).

While we observed alterations in immune cell recruitment and immunopathology in M. tuberculosis infected mice shortly after acute $P$. yoelii co-infection, differences in immunopathology and cellular immune responses between $M$. tuberculosis and co-infected mice were no longer apparent 150 days later. This indicates that $P$. yoelii co-infection had only a transient effect on $\mathrm{Tb}$ disease severity, which is supported by the fact that mice from both groups did not show clinical signs of disease or premature death throughout the entire observation period. The reason for this is most likely the transient nature of the $P$. yoelii infection. Parasitemia is resolved within 3-4 weeks and consequently, $P$. yoelii induced immune responses decline over time. Moreover, hemozoin, which probably contributes to increased inflammation in the co-infected lungs, is known to be redistributed to liver and spleen over time (Levesque et al., 1999; Frita et al., 2012; Deroost et al., 2013).

Mice in our model only experienced one episode of Plasmodium infection. In contrast, people living in malariaendemic settings are constantly reinfected with malaria parasites. Hence, these people potentially suffer from continuous immune modulation, which might increase their susceptibility to $\mathrm{Tb}$. Studying malaria reinfections in our mouse model is complicated by the fact that C57BL/ 6 mice after recovering from parasitemia, become resistant to reinfection with P. yoelii (Lucas et al., 1993).

\section{REFERENCES}

Alaniz, R. C., Sandall, S., Thomas, E. K., and Wilson, C. B. (2004). Increased dendritic cell numbers impair protective immunity to intracellular bacteria despite augmenting antigen-specific CD8+ T lymphocyte responses. J. Immunol. 172, 3725-3735. doi: 10.4049/jimmunol.172.6.3725

Algood, H. M., Lin, P. L., and Flynn, J. L. (2005). Tumor necrosis factor and chemokine interactions in the formation and maintenance of granulomas in tuberculosis. Clin. Infect. Dis. 41(Suppl. 3), S189-S193. doi: 10.1086/429994
This does not reflect the situation in humans where immunity to malaria develops relatively slowly and sterile immunity is probably never achieved (Langhorne et al., 2008). However, the fact that one single episode of $P$. yoelii co-infection is able to modulate immune responses and inflammation in the lungs of M. tuberculosis infected mice indicates that constant exposure to malaria could be a risk factor for Tb patients.

Importantly, our observations indicate that the full resolution of malaria-related syndromes was delayed in $M$. tuberculosis infected mice. The fact that co-infected mice, although able to clear parasitemia equally well, showed a delay in the resolution of splenomegaly and clearance of hemozoin from spleen and liver indicates that immune cell function in the spleen is modulated long-term. Since the spleen is the central organ for immunity in malaria, the question arises as to whether immunity to $P$. yoelii reinfection is established and/or maintained in $M$. tuberculosis infected mice. This important question will be addressed in our lab in future studies. These studies shall also reveal if recurrent $P$. yoelii infections will cause permanent immune modulation and ultimate loss of control of chronic M. tuberculosis infection.

In conclusion, one episode of $P$. yoelii co-infection transiently exacerbated $\mathrm{Tb}$ disease severity but had no longterm consequences on disease progression and survival of M. tuberculosis infected mice.

\section{AUTHOR CONTRIBUTIONS}

Conceived and designed the experiments: BS, JB, JBe, and TJ. Performed the experiments: JB, LE, and BS. Analyzed the data: JB and JBe. Contributed reagents/materials/analysis tools: BS, TJ, and JBe. Wrote the paper: BS and JB.

\section{ACKNOWLEDGMENT}

This work was supported by the Leibniz Center Infection. The publication of this article was funded by the Open Access fund of the Leibniz Association.

\section{SUPPLEMENTARY MATERIAL}

The Supplementary Material for this article can be found online at: http://journal.frontiersin.org/article/10.3389/fmicb. 2016.00152

Antonelli, L. R., Gigliotti Rothfuchs, A., Goncalves, R., Roffe, E., Cheever, A. W., Bafica, A., et al. (2010). Intranasal Poly-IC treatment exacerbates tuberculosis in mice through the pulmonary recruitment of a pathogenpermissive monocyte/macrophage population. J. Clin. Invest. 120, 1674-1682. doi: 10.1172/JCI40817

Bates, M., Marais, B. J., and Zumla, A. (2015). Tuberculosis comorbidity with communicable and noncommunicable diseases. Cold Spring Harb. Perspect. Med 5, a017889. doi: 10.1101/cshperspect.a0 17889 
Beisiegel, M., Kursar, M., Koch, M., Loddenkemper, C., Kuhlmann, S., Zedler, U., et al. (2009). Combination of host susceptibility and virulence of Mycobacterium tuberculosis determines dual role of nitric oxide in the protection and control of inflammation. J. Infect. Dis. 199, 1222-1232. doi: $10.1086 / 597421$

Belyaev, N. N., Biro, J., Langhorne, J., and Potocnik, A. J. (2013). Extramedullary myelopoiesis in malaria depends on mobilization of myeloid-restricted progenitors by IFN-gamma induced chemokines. PLoS Pathog. 9:e1003406. doi: 10.1371/journal.ppat.1003406

Bodnar, K. A., Serbina, N. V., and Flynn, J. L. (2001). Fate of Mycobacterium tuberculosis within murine dendritic cells. Infect. Immun. 69, 800-809. doi: 10.1128/IAI.69.2.800-809.2001

Bomford, R., and Wedderburn, N. (1973). Depression of immune response to Moloney leukaemia virus by malarial infection. Nature 242, 471-473. doi: 10.1038/242471a0

Borden, E. C., Sen, G. C., Uze, G., Silverman, R. H., Ransohoff, R. M., Foster, G. R., et al. (2007). Interferons at age 50: past, current and future impact on biomedicine. Nat. Rev. Drug Discov. 6, 975-990. doi: 10.1038/nrd 2422

Bousema, T., Okell, L., Felger, I., and Drakeley, C. (2014). Asymptomatic malaria infections: detectability, transmissibility and public health relevance. Nat. Rev. Microbiol. 12, 833-840. doi: 10.1038/nrmicro 3364

Boussiotis, V. A., Tsai, E. Y., Yunis, E. J., Thim, S., Delgado, J. C., Dascher, C. C., et al. (2000). IL-10-producing $\mathrm{T}$ cells suppress immune responses in anergic tuberculosis patients. J. Clin. Invest. 105, 1317-1325. doi: 10.1172/JCI9918

Brasseur, P., Agrapart, M., Ballet, J. J., Druilhe, P., Warrell, M. J., and Tharavanij, S. (1983). Impaired cell-mediated immunity in Plasmodium falciparum-infected patients with high-parasitemia and cerebral malaria. Clin. Immunol. Immunopathol. 27, 38-50. doi: 10.1016/0090-1229(83)90054-5

Chan, J., Tanaka, K., Carroll, D., Flynn, J., and Bloom, B. R. (1995). Effects of nitric oxide synthase inhibitors on murine infection with Mycobacterium tuberculosis Infect. Immun. 63, 736-740.

Chan, J., Xing, Y., Magliozzo, R. S., and Bloom, B. R. (1992). Killing of virulent Mycobacterium tuberculosis by reactive nitrogen intermediates produced by activated murine macrophages. J. Exp. Med. 175, 1111-1122. doi: 10.1084/jem.175.4.1111

Clark, I. A., Allison, A. C., and Cox, F. E. (1976). Protection of mice against Babesia and Plasmodium with BCG. Nature 259, 309-311. doi: 10.1038/259 $309 \mathrm{a} 0$

Colombatti, R., Penazzato, M., Bassani, F., Vieira, C. S., Lourenco, A. A., Vieira, F., et al. (2011). Malaria prevention reduces in-hospital mortality among severely ill tuberculosis patients: a three-step intervention in Bissau, Guinea-Bissau. BMC Infect. Dis. 11:57. doi: 10.1186/1471-2334-11-57

Cook, I. F. (1985). Herpes zoster in children following malaria. J. Trop. Med. Hyg $88,261-264$

Cooper, A. M., Pearl, J. E., Brooks, J. V., Ehlers, S., and Orme, I. M. (2000). Expression of the nitric oxide synthase 2 gene is not essential for early control of Mycobacterium tuberculosis in the murine lung. Infect. Immun. 68, 6879-6882. doi: 10.1128/IAI.68.12.6879-6882.2000

Correa, M., Narayanan, P. R., and Miller, H. C. (1980). Suppressive activity of splenic adherent cells from Plasmodium chabaudi-infected mice. J. Immunol. $125,749-754$.

Couper, K. N., Blount, D. G., and Riley, E. M. (2008a). IL-10: the master regulator of immunity to infection. J. Immunol. 180, 5771-5777. doi: 10.4049/jimmunol.180.9.5771

Couper, K. N., Blount, D. G., Wilson, M. S., Hafalla, J. C., Belkaid, Y., Kamanaka, M., et al. (2008b). IL-10 from CD4CD25Foxp3CD127 adaptive regulatory $\mathrm{T}$ cells modulates parasite clearance and pathology during malaria infection. PLoS Pathog. 4:e1000004. doi: 10.1371/journal.ppat.10 00004

Cunnington, A. J., and Riley, E. M. (2010). Suppression of vaccine responses by malaria: insignificant or overlooked? Expert Rev. Vaccines 9, 409-429. doi: 10.1586/erv.10.16

Deroost, K., Tyberghein, A., Lays, N., Noppen, S., Schwarzer, E., Vanstreels, E., et al. (2013). Hemozoin induces lung inflammation and correlates with malariaassociated acute respiratory distress syndrome. Am. J. Respir. Cell Mol. Biol. 48, 589-600. doi: 10.1165/rcmb.2012-0450OC
Desvignes, L., and Ernst, J. D. (2009). Interferon-gamma-responsive nonhematopoietic cells regulate the immune response to Mycobacterium tuberculosis. Immunity 31, 974-985. doi: 10.1016/j.immuni.2009.10.007

deWalick, S., Amante, F. H., McSweeney, K. A., Randall, L. M., Stanley, A. C., Haque, A., et al. (2007). Cutting edge: conventional dendritic cells are the critical APC required for the induction of experimental cerebral malaria. J. Immunol. 178, 6033-6037. doi: 10.4049/jimmunol.178.10.6033

Enwere, G. C., Ota, M. O., and Obaro, S. K. (1999). The host response in malaria and depression of defence against tuberculosis. Ann. Trop. Med. Parasitol. 93, 669-678. doi: 10.1080/00034989957907

Feng, C. G., Kaviratne, M., Rothfuchs, A. G., Cheever, A., Hieny, S., Young, H. A., et al. (2006). NK cell-derived IFN-gamma differentially regulates innate resistance and neutrophil response in $\mathrm{T}$ cell-deficient hosts infected with Mycobacterium tuberculosis. J. Immunol. 177, 7086-7093. doi: 10.4049/jimmunol.177.10.7086

Forbes, E. K., Sander, C., Ronan, E. O., McShane, H., Hill, A. V., Beverley, P. C., et al. (2008). Multifunctional, high-level cytokine-producing Th1 cells in the lung, but not spleen, correlate with protection against Mycobacterium tuberculosis aerosol challenge in mice. J. Immunol. 181, 4955-4964. doi: 10.4049/jimmunol.181.7.4955

Freitas do Rosario, A. P., Lamb, T., Spence, P., Stephens, R., Lang, A., Roers, A., et al. (2012). IL-27 promotes IL-10 production by effector Th1 CD4+ T cells: a critical mechanism for protection from severe immunopathology during malaria infection. J. Immunol. 188, 1178-1190. doi: 10.4049/jimmunol.1102755

Frita, R., Carapau, D., Mota, M. M., and Hanscheid, T. (2012). In vivo hemozoin kinetics after clearance of Plasmodium berghei infection in mice. Malar. Res. Treat. 2012, 373086. doi: 10.1155/2012/373086

Gazzinelli, R. T. I, Oswald, P., James, S. L., and Sher, A. (1992). IL-10 inhibits parasite killing and nitrogen oxide production by IFN-gamma-activated macrophages. J. Immunol. 148, 1792-1796.

Greenwood, B. M., Bradley-Moore, A. M., Bryceson, A. D., and Palit, A. (1972). Immunosuppression in children with malaria. Lancet 1, 169-172. doi: 10.1016/S0140-6736(72)90569-7

Harding, J. S., Rayasam, A., Schreiber, H. A., Fabry, Z., and Sandor, M. (2015). Mycobacterium-infected dendritic cells disseminate granulomatous inflammation. Sci. Rep. 5, 15248. doi: 10.1038/srep15248

Hawkes, M., Li, X., Crockett, M., Diassiti, A., Conrad Liles, W., Liu, J., et al. (2010). Malaria exacerbates experimental mycobacterial infection in vitro and in vivo. Microbes Infect. 12, 864-874. doi: 10.1016/j.micinf.2010.05.013

Herbst, S., Schaible, U. E., and Schneider, B. E. (2011). Interferon gamma activated macrophages kill mycobacteria by nitric oxide induced apoptosis. PLoS ONE 6:e19105. doi: 10.1371/journal.pone.0019105

Hviid, L., Theander, T. G., Abu-Zeid, Y. A., Abdulhadi, N. H., Jakobsen, P. H., Saeed, B. O., et al. (1991). Loss of cellular immune reactivity during acute Plasmodium falciparum malaria. FEMS Microbiol. Immunol. 3, 219-227. doi: 10.1111/j.1574-6968.1991.tb04218.x

Junqueira-Kipnis, A. P., Kipnis, A., Jamieson, A., Juarrero, M. G., Diefenbach, A., Raulet, D. H., et al. (2003). NK cells respond to pulmonary infection with Mycobacterium tuberculosis, but play a minimal role in protection. J. Immunol. 171, 6039-6045. doi: 10.4049/jimmunol.171.11.6039

Kleinschmidt, I., Schwabe, C., Benavente, L., Torrez, M., Ridl, F. C., Segura, J. L., et al. (2009). Marked increase in child survival after four years of intensive malaria control. Am. J. Trop. Med. Hyg. 80, 882-888.

Kopf, M., Schneider, C., and Nobs, S. P. (2015). The development and function of lung-resident macrophages and dendritic cells. Nat. Immunol. 16, 36-44. doi: 10.1038/ni.3052

Korbel, D. S., Schneider, B. E., and Schaible, U. E. (2008). Innate immunity in tuberculosis: myths and truth. Microbes Infect. 10, 995-1004. doi: 10.1016/j.micinf.2008.07.039

Lancelin, W., and Guerrero-Plata, A. (2011). Isolation of mouse lung dendritic cells. J. Vis. Exp. 22, 3563. doi: 10.3791/3563

Langhorne, J., Albano, F. R., Hensmann, M., Sanni, L., Cadman, E., Voisine, C., et al. (2004). Dendritic cells, pro-inflammatory responses, and antigen presentation in a rodent malaria infection. Immunol. Rev. 201, 35-47. doi: 10.1111/j.0105-2896.2004.00182.x

Langhorne, J., Ndungu, F. M., Sponaas, A. M., and Marsh, K. (2008). Immunity to malaria: more questions than answers. Nat. Immunol. 9, 725-732. doi: 10.1038/ni.f.205 
Leisewitz, A. L., Rockett, K., and Kwiatkowski, D. (2008). BCG-malaria coInfection has paradoxical effects on $\mathrm{C} 57 \mathrm{BL} / 6$ and $\mathrm{A} / \mathrm{J}$ mouse strains. Parasite Immunol. 30, 1-12. doi: 10.1111/j.1365-3024.2007.00983.x

Levesque, M. A., Sullivan, A. D., and Meshnick, S. R. (1999). Splenic and hepatic hemozoin in mice after malaria parasite clearance. J. Parasitol. 85, 570-573. doi: $10.2307 / 3285800$

Lewin, A., Freytag, B., Meister, B., Sharbati-Tehrani, S., Schafer, H., and Appel, B. (2003). Use of a quantitative TaqMan-PCR for the fast quantification of mycobacteria in broth culture, eukaryotic cell culture and tissue. J. Vet. Med. B Infect. Dis. Vet. Public Health 50, 505-509. doi: 10.1046/j.14390450.2003.00715.x

Lucas, B., Engel, A., Camus, D., and Haque, A. (1993). Plasmodium yoelii in mice: antigen reactivity of CD4- and CD8-bearing T cells. Cell. Immunol. 150, 59-71. doi: $10.1006 /$ cimm.1993.1178

Mabey, D. C., Brown, A., and Greenwood, B. M. (1987). Plasmodium falciparum malaria and Salmonella infections in Gambian children. J. Infect. Dis. 155, 1319-1321. doi: 10.1093/infdis/155.6.1319

MacMicking, J. D., North, R. J., LaCourse, R., Mudgett, J. S., Shah, S. K., and Nathan, C. F. (1997). Identification of nitric oxide synthase as a protective locus against tuberculosis. Proc. Natl. Acad. Sci. U.S.A. 94, 5243-5248. doi: 10.1073/pnas.94.10.5243

Marriott, I., Hammond, T. G., Thomas, E. K., and Bost, K. L. (1999). Salmonella efficiently enter and survive within cultured CD11c+ dendritic cells initiating cytokine expression. Eur. J. Immunol. 29, 1107-1115. doi: 10.1002/(SICI)15214141(199904)29:04<1107::AID-IMMU1107>3.0.CO;2-0

Matsumoto, S., Yukitake, H., Kanbara, H., Yamada, H., Kitamura, A., and Yamada, T. (2000). Mycobacterium bovis bacillus calmette-guerin induces protective immunity against infection by Plasmodium yoelii at blood-stage depending on shifting immunity toward Th1 type and inducing protective IgG2a after the parasite infection. Vaccine 19, 779-787. doi: 10.1016/S0264410X(00)00257-7

Medema, J. P., Schuurhuis, D. H., Rea, D., van Tongeren, J., de Jong, J., Bres, S. A., et al. (2001). Expression of the serpin serine protease inhibitor 6 protects dendritic cells from cytotoxic $\mathrm{T}$ lymphocyte-induced apoptosis: differential modulation by T helper type 1 and type 2 cells. J. Exp. Med. 194, 657-667. doi: 10.1084/jem.194.5.657

Melrose, J., Tsurushita, N., Liu, G., and Berg, E. L. (1998). IFN-gamma inhibits activation-induced expression of $\mathrm{E}$ - and P-selectin on endothelial cells. J. Immunol. 161, 2457-2464.

Mishra, B. B., Rathinam, V. A., Martens, G. W., Martinot, A. J., Kornfeld, H., Fitzgerald, K. A., et al. (2013). Nitric oxide controls the immunopathology of tuberculosis by inhibiting NLRP3 inflammasome-dependent processing of IL-1beta. Nat. Immunol. 14, 52-60. doi: 10.1038/ni.2474

Mueller, A.-K., Behrends, J., Hagens, K., Mahlo, J., Schaible, U. E., and Schneider, B. E. (2012). Natural transmission of Plasmodium berghei exacerbates chronic tuberculosis in an experimental Co-infection model. PLoS ONE 7:e48110. doi: 10.1371/journal.pone.0048110

Murphy, J. R. (1981). Host defenses in murine malaria: nonspecific resistance to Plasmodium berghei generated in response to Mycobacterium bovis infection or Corynebacterium parvum stimulation. Infect. Immun. 33, 199-211.

Murray, C. J., Rosenfeld, L. C., Lim, S. S., Andrews, K. G., Foreman, K. J., Haring, D., et al. (2012). Global malaria mortality between 1980 and 2010: a systematic analysis. Lancet 379, 413-431. doi: 10.1016/S0140-6736(12)60034-8

Murray, P. J., Wang, L., Onufryk, C., Tepper, R. I., and Young, R. A. (1997). T cell-derived IL-10 antagonizes macrophage function in mycobacterial infection. J. Immunol. 158, 315-321.

Murray, P. J., and Young, R. A. (1999). Increased antimycobacterial immunity in interleukin-10-deficient mice. Infect. Immun. 67, 3087-3095.

Nandi, B., and Behar, S. M. (2011). Regulation of neutrophils by interferongamma limits lung inflammation during tuberculosis infection. J. Exp. Med. 208, 2251-2262. doi: 10.1084/jem.20110919

Ocana-Morgner, C., Mota, M. M., and Rodriguez, A. (2003). Malaria blood stage suppression of liver stage immunity by dendritic cells. J. Exp. Med. 197, 143-151. doi: 10.1084/jem.20021072

O'Garra, A., Redford, P. S., McNab, F. W., Bloom, C. I., Wilkinson, R. J., and Berry, M. P. (2013). The immune response in tuberculosis. Annu. Rev. Immunol. 31, 475-527. doi: 10.1146/annurev-immunol-032712-0 95939
Orengo, J. M., Wong, K. A., Ocana-Morgner, C., and Rodriguez, A. (2008). A Plasmodium yoelii soluble factor inhibits the phenotypic maturation of dendritic cells. Malar. J. 7, 254. doi: 10.1186/1475-2875-7-254

Page, K. R., Jedlicka, A. E., Fakheri, B., Noland, G. S., Kesavan, A. K., Scott, A. L., et al. (2005). Mycobacterium-induced potentiation of type 1 immune responses and protection against malaria are host specific. Infect. Immun. 73, 8369-8380. doi: 10.1128/IAI.73.12.8369-8380.2005

Parra, M., Liu, X., Derrick, S. C., Yang, A., Tian, J., Kolibab, K., et al. (2013). Molecular analysis of non-specific protection against murine malaria induced by BCG vaccination. PLoS ONE 8:e66115. doi: 10.1371/journal.pone.0066115

Parroche, P., Lauw, F. N., Goutagny, N., Latz, E., Monks, B. G., Visintin, A., et al. (2007). Malaria hemozoin is immunologically inert but radically enhances innate responses by presenting malaria DNA to Toll-like receptor 9. Proc. Natl. Acad. Sci. U.S.A. 104, 1919-1924. doi: 10.1073/pnas.0608745104

Redford, P. S., Boonstra, A., Read, S., Pitt, J., Graham, C., Stavropoulos, E., et al. (2010). Enhanced protection to Mycobacterium tuberculosis infection in IL-10deficient mice is accompanied by early and enhanced Th1 responses in the lung. Eur. J. Immunol. 40, 2200-2210. doi: 10.1002/eji.201040433

Roach, D. R., Bean, A. G., Demangel, C., France, M. P., Briscoe, H., and Britton, W. J. (2002). TNF regulates chemokine induction essential for cell recruitment, granuloma formation, and clearance of mycobacterial infection. J. Immunol. 168, 4620-4627. doi: 10.4049/jimmunol.168.9.4620

Roth, A., Garly, M. L., Jensen, H., Nielsen, J., and Aaby, P. (2006a). Bacillus Calmette-Guerin vaccination and infant mortality. Expert Rev. Vaccines 5, 277-293. doi: 10.1586/14760584.5.2.277

Roth, A. E., Stensballe, L. G., Garly, M. L., and Aaby, P. (2006b). Beneficial nontargeted effects of BCG-ethical implications for the coming introduction of new TB vaccines. Tuberculosis (Edinb.) 86, 397-403. doi: 10.1016/j.tube.2006.02.001

Roth, A., Gustafson, P., Nhaga, A., Djana, Q., Poulsen, A., Garly, M. L., et al. (2005). BCG vaccination scar associated with better childhood survival in Guinea-Bissau. Int. J. Epidemiol. 34, 540-547. doi: 10.1093/ije/dyh392

Schreiber, T., Ehlers, S., Heitmann, L., Rausch, A., Mages, J., Murray, P. J., et al. (2009). Autocrine IL-10 induces hallmarks of alternative activation in macrophages and suppresses antituberculosis effector mechanisms without compromising T cell immunity. J. Immunol. 183, 1301-1312. doi: 10.4049/jimmunol.0803567

Scott, C. P., Kumar, N., Bishai, W. R., and Manabe, Y. C. (2004). Short report: modulation of Mycobacterium tuberculosis infection by Plasmodium in the murine model. Am. J. Trop. Med. Hyg. 70, 144-148.

Shanks, G. D., Hay, S. I., and Bradley, D. J. (2008). Malaria's indirect contribution to all-cause mortality in the Andaman Islands during the colonial era. Lancet Infect. Dis. 8, 564-570. doi: 10.1016/S1473-3099(08)70130-0

Shann, F. (2010). The non-specific effects of vaccines. Arch. Dis. Child. 95, 662-667. doi: $10.1136 /$ adc.2009.157537

Shann, F. (2011). The nonspecific effects of vaccines and the expanded program on immunization. J. Infect. Dis. 204, 182-184. doi: 10.1093/infdis/jir244

Smrkovski, L. L., and Strickland, G. T. (1978). Rodent malaria: BCG-induced protection and immunosuppression. J. Immunol. 121, 1257-1261.

Urban, B. C., and Todryk, S. (2006). Malaria pigment paralyzes dendritic cells. J. Biol. 5, 4. doi: 10.1186/jbiol37

Van den Steen, P. E., Geurts, N., Deroost, K., Van Aelst, I., Verhenne, S., Heremans, H., et al. (2010). Immunopathology and dexamethasone therapy in a new model for malaria-associated acute respiratory distress syndrome. Am. J. Respir. Crit. Care Med. 181, 957-968.

Voisine, C., Mastelic, B., Sponaas, A. M., and Langhorne, J. (2010). Classical CD11c+ dendritic cells, not plasmacytoid dendritic cells, induce $\mathrm{T}$ cell responses to Plasmodium chabaudi malaria. Int. J. Parasitol. 40, 711-719. doi: 10.1016/j.ijpara.2009.11.005

Walther, B., Miles, D. J., Waight, P., Palmero, M. S., Ojuola, O., Touray, E. S., et al. (2012). Placental malaria is associated with attenuated CD4 T-cell responses to tuberculin PPD 12 months after BCG vaccination. BMC Infect. Dis. 12:6. doi: 10.1186/1471-2334-12-6

Warren, H. S., and Weidanz, W. P. (1976). Malarial immunodepression in vitro: adherent spleen cells are functionally defective as accessory cells in the response to horse erythrocytes. Eur. J. Immunol. 6, 816-819. doi: 10.1002/eji.1830061112

Whittle, H. C., Brown, J., Marsh, K., Greenwood, B. M., Seidelin, P., Tighe, H., et al. (1984). T-cell control of Epstein-Barr virus-infected B cells is lost during P. falciparum malaria. Nature 312, 449-450. doi: 10.1038/312449a0 
WHO (2015). Global Tuberculosis Report 2015. Geneva: World Health Organization.

Williamson, W. A., and Greenwood, B. M. (1978). Impairment of the immune response to vaccination after acute malaria. Lancet 1, 1328-1329. doi: 10.1016/S0140-6736(78)92403-0

Wolf, A. J., Desvignes, L., Linas, B., Banaiee, N., Tamura, T., Takatsu, K., et al. (2008). Initiation of the adaptive immune response to Mycobacterium tuberculosis depends on antigen production in the local lymph node, not the lungs. J. Exp. Med. 205, 105-115. doi: 10.1084/jem.20071367

Wolf, A. J., Linas, B., Trevejo-Nunez, G. J., Kincaid, E., Tamura, T., Takatsu, K., et al. (2007). Mycobacterium tuberculosis infects dendritic cells with high frequency and impairs their function in vivo. J. Immunol. 179, 2509-2519. doi: 10.4049/jimmunol.179.4.2509

Wykes, M. N., Liu, X. Q., Beattie, L., Stanisic, D. I., Stacey, K. J., Smyth, M. J., et al. (2007). Plasmodium strain determines dendritic cell function essential for survival from malaria. PLoS Pathog. 3:e96. doi: 10.1371/journal.ppat.0030096
Zhou, Z., Connell, M. C., and MacEwan, D. J. (2007). TNFR1-induced NF-kappaB, but not ERK, p38MAPK or JNK activation, mediates TNF-induced ICAM-1 and VCAM-1 expression on endothelial cells. Cell. Signal. 19, 1238-1248. doi: 10.1016/j.cellsig.2006.12.013

Conflict of Interest Statement: The authors declare that the research was conducted in the absence of any commercial or financial relationships that could be construed as a potential conflict of interest.

Copyright (c) 2016 Blank, Eggers, Behrends, Jacobs and Schneider. This is an openaccess article distributed under the terms of the Creative Commons Attribution License (CC BY). The use, distribution or reproduction in other forums is permitted, provided the original author(s) or licensor are credited and that the original publication in this journal is cited, in accordance with accepted academic practice. No use, distribution or reproduction is permitted which does not comply with these terms. 